Document downloaded from:

http://hdl.handle.net/10251/139763

This paper must be cited as:

Bertolesi, E.; Milani, G.; Fagone, M.; Rotunno, T.; Grande, E. (01-1). Micro-mechanical FE numerical model for masonry curved pillars reinforced with FRP strips subjected to single lap shear tests. Composite Structures. 201:916-931. https://doi.org/10.1016/j.compstruct.2018.06.111

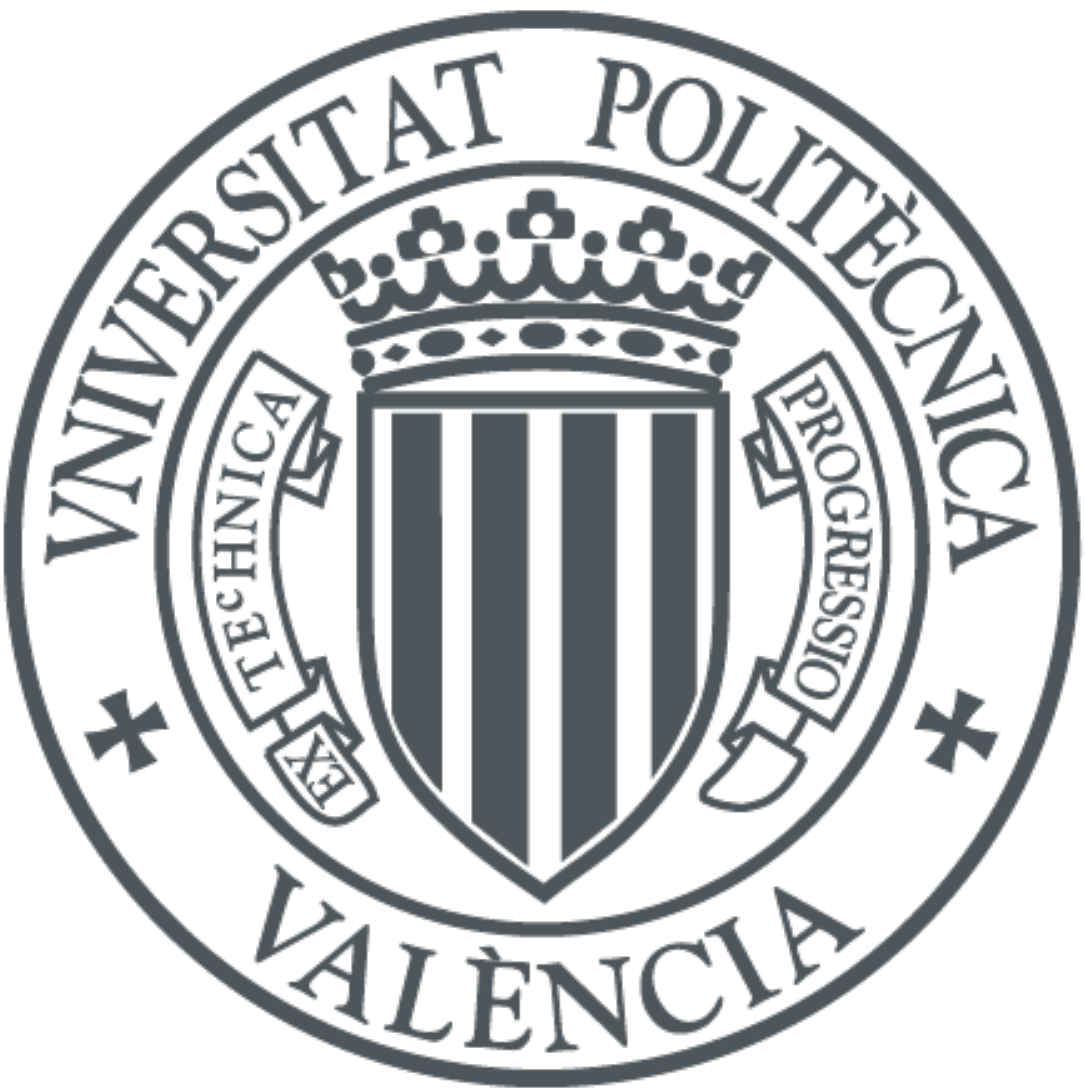

The final publication is available at

https://doi.org/10.1016/j.compstruct.2018.06.111

Copyright Elsevier

Additional Information 


\title{
Micro-mechanical FE numerical model for masonry curved pillars reinforced with FRP strips subjected to single lap shear tests
}

\author{
Elisa BERTOLESI ${ }^{(1)}$, Gabriele MILANI ${ }^{*(2)}$, Mario FAGONE ${ }^{(3)}$, Tommaso ROTUNNO $^{(4)}$, Ernesto \\ GRANDE $^{(5)}$ \\ ICITECH, Universitat Politècnica de Valencia, Camino de Vera s/n 46022, Valencia (Spain) \\ (2) Department of Architecture, Built environment and Construction engineering (ABC), Politecnico di Milano,
} Piazza Leonardo da Vinci 32, 20133, Milan (Italy)

(3) Dipartimento di Ingegneria Civile e Ambientale (DICeA), Università degli Studi di Firenze, Piazza Brunelleschi 6, 50121 Florence (Italy)

(4) Dipartimento di Architettura (DiDA), Università degli Studi di Firenze, Piazza Brunelleschi 6, 50121 Florence (Italy)

(5) Department of Sustainability Engineering, University Guglielmo Marconi, Via Plinio 44, 00193 Rome (Italy)

* $\quad$ corresponding author, e-mail: gabriele.milani@polimi.it

\begin{abstract}
The present paper discusses the results obtained using a micro-mechanical FE numerical model used to study the bond behavior of some curved specimens strengthened by Fiber Reinforced Polymer (FRP) composite materials. The numerical model, implemented into the FE code Abaqus, is a sophisticated micro-modelling (heterogeneous) approach, where bricks and mortar are meshed separately by means of 4-noded plane strain elements exhibiting distinct damage in tension and compression, FRP is assumed elastic and an elastic uncoupled cohesive layer is interposed between FRP reinforcement and masonry pillar. The experimental investigation considered to benchmark the numerical approach is aimed at characterizing the influence of normal stresses induced by curved supports on the stress-transfer mechanism of FRP materials. To this scope some single lap shear tests performed at the University of Florence on FRP reinforced curved pillars with two different curvature radii $(1500$ and $3000 \mathrm{~mm})$ are here considered. The obtained numerical results obtained show a promising match with experimental evidences, in terms of elastic stiffness, peak loads and post-peak behavior. Indeed, the proposed approach allows to correctly account for important local effects, such as the effect of FRP-masonry interfacial normal stresses on the global delamination strength and the distribution of damage in the pillar volume. By using the proposed modelling approach, comprehensive numerical sensitivity analyses to investigate the role played by the curvature on the ultimate delamination strength, are also presented in the paper.
\end{abstract}

Keywords: heterogeneous damage-plasticity FE model; validation against experiments; curvature effect; masonry; FRP; delamination

\section{Introduction}

Fiber Reinforced Polymer (FRP) materials have been extensively used in the last decades for repairing and upgrading of concrete and masonry structures. Nowadays, such strengthening systems comprise different types of fiber textiles (i.e. carbon or glass fibers) arranged in various forms but always glued by means of a thin layer of epoxy resin. The final composite material to be used on load bearing elements is characterized 
by well-known properties, for instance: high tensile strength, high elastic modulus, lightness and easiness in the application [1]. From a mechanical point of view, the behavior of Fiber Reinforced Polymer composites has been extensively studied by various research groups. In the technical literature, there are several studies available, which investigated the bond performance of FRP composite materials and mostly the well-known delamination. As stated in [2]-[6], this is a typical failure mechanism of FRP materials, which involves the removal of a thin layer of the support. Indeed, their bond behavior is essentially governed by a first elastic phase followed by a sudden brittle detachment of the strengthening from the support upon which it has been applied. Some studies have been developed to analyze the effect of FRP strengthening on real structures, for instance [7]-[9]. Conversely, experimental studies dealing with curved supports and facing with the interaction of normal and tangential stresses as a consequence of the convex/concave geometry are still at their initial stages. Only recently, few research groups have started to analyze the beneficial or negative effect produced by the curvature of support on the load carrying capacity and ductility. The interest on this topic is justified by the need to use FRP to reinforce curved structural elements, as for instance masonry vaults and arches [10]-[16]. From a practical point of view, the correct determination of the ultimate collapse load and the consequent increase of the overall load carrying capacity of curved reinforced structures is fundamental, but up to now, only few recommendations are available in the reference legislation (CNR DT 200) [17] and the space dedicated to such problem is still impressively limited.

From a numerical point of view, the analyses of FRP reinforced structures has been addressed with several numerical and analytical approaches, characterized by different grades of accuracy, see for instance [18]-[21] where the interested reader is referred to for further details on pros and cons of each model. One of the most common numerical strategies is based on the use of zero-thickness interfaces placed between the FRP strengthening and the substrate material to repair [22]-[25]. In this specific case, the assumption is that a weak plane of slip exists between support and reinforcement. Usually, the interaction between the FRP and the underlying element is governed by the peak tangential strength and the fracture energy associated with Mode II. In this context, bilinear stress-slip laws can be adopted to describe both the normal and tangential behaviors of the interface. It is worth mentioning that a complete description of the collapse mechanism can be achieved mostly with 3D models, which allow evaluating the damage diffusion inside the constituent materials. Obviously, a full 3D approach with damage is too ambitious and very demanding from a computational point of view, because of a large number of FEs is required to properly discretize the contact zone and the issues related to softening. A reduction of the computational effort can be accomplished removing the assumption of the interface layer between the FRP and the support. In this regard, the global performance of a reinforced pillar is strongly influenced by the tensile properties of the materials which constitute the support [26]-[28]. The present work partially follows this last research line, but presents a novel combined FE strategy where the masonry pillar is meshed with a 2D heterogeneous micro-modelling approach with bulk damage for mortar and bricks, and a soft elastic interface is interposed between FRP and support, to properly reproduce the exact deformability exhibited by the tested specimens. The paper is aimed at studying, in particular, the detrimental or positive effect produced by the development of tensile or 
compressive normal stresses induced by the curvature of the pillar surface, as well as its influence on the FRP global performance. In addition, the paper is aimed at investigating the key role played by the mechanical properties of masonry constituent materials, when FRP composites are externally applied for strengthening and to predict with a computationally inexpensive FE model the debonding mechanism of FRP. To this scope, curved reinforced masonry specimens are modelled meshing into FEs the constituent materials separately, using elastic (FRP) or inelastic (mortar and bricks) 4-noded plane strain FEs, with an elastic cohesive interface between the FRPs and the masonry support. An isotropic damage material model already implemented in the commercial FE software used to carry out simulations (Abaqus) is assumed for both bricks and mortar joints. Their inelastic and elastic properties are tuned in agreement with data put available from the experimental campaign reported in [29]. Results obtained numerically show how the present FE approach is able to capture with high accuracy the global behavior found experimentally (loaddisplacement curves), as well as the local failure modes. The effect of the surface curvature is also discussed in detail, with particular regard to the bond performance.

The computational effort needed by the FE model proposed is relatively limited. Hence, full sensitivity analyses are carried out changing both the surface curvature and constituent materials mechanical properties. Such investigation offers food for thought on possible simplified formulas predictive of the actual delamination strength in presence of curved surfaces. Numerical simulations are replicated for 6 new curvature radii plus the flat case, providing the numerical trends (as a function of the curvature radius) for peak and elastic limit loads. One of the main findings is that the compression fracture energy of the bricks is crucial for a correct determination of the peak delamination strength. Conversely and as expected, the elastic limit strength does not depend on the curvature radius, whereas the residual strength is independent from the fracture energy chosen for the constituent materials.

\section{Case studies}

A comprehensive experimental investigation carried out at the University of Florence and fully described in [29] is here considered to benchmark the numerical model. Four series of FRP reinforced curved masonry pillars subjected to single lap shear tests and differing for the curvature radius (equal to 1500 and $3000 \mathrm{~mm}$ ) and the position of the reinforcement (intrados and extrados) are studied. Specimens are here labelled using the following alphanumeric code: CXY N, where $\mathrm{X}$ indicates the curvature radius of the surface (so that $\mathrm{A}$ indicates a radius of $1500 \mathrm{~mm}$ and $\mathrm{B}$ one of $3000 \mathrm{~mm}$ ), $\mathrm{Y}$ identifies the position of the strengthening ( $\mathrm{E}=$ extrados and $\mathrm{I}=$ intrados) and $\mathrm{N}$ is used to number the replicates. 


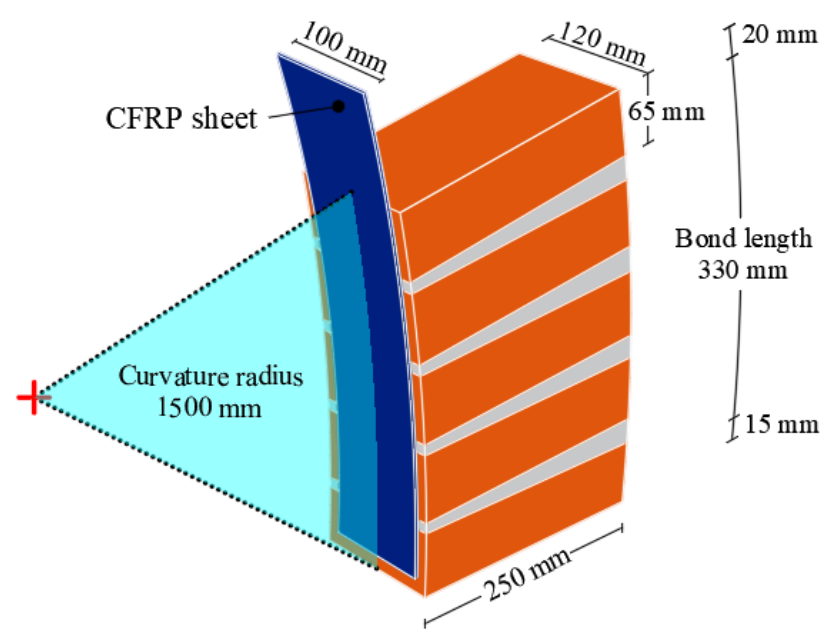

$-\mathrm{a}$

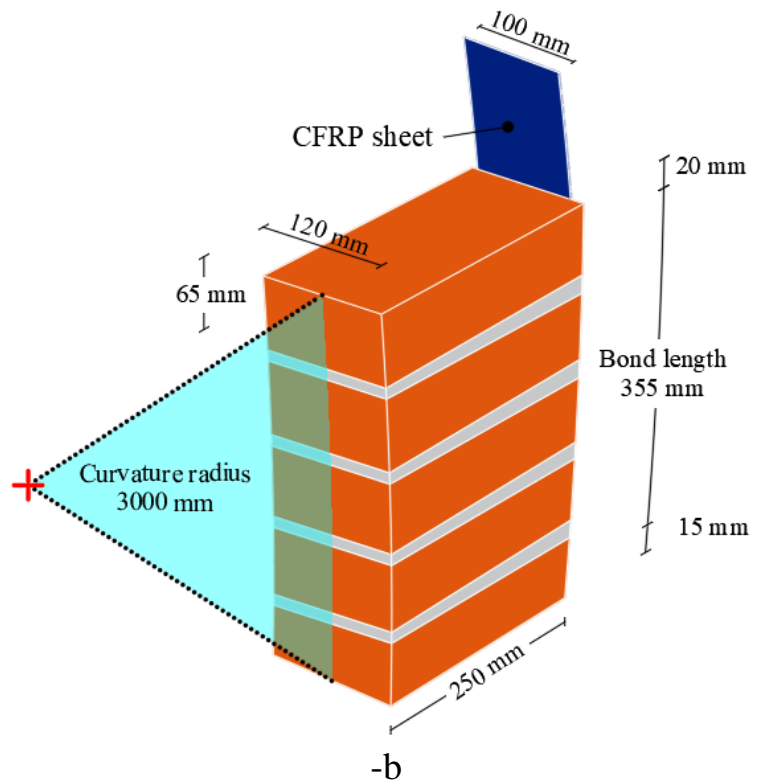

$-\mathrm{b}$

Figure 1: Curved specimen configurations, geometry of the CAI (-a) and CBE (-b) masonry specimens.

Considering that in [29] each series was constituted by 5 replicates, a total of 20 pillars was tested. Pillars were built with 5 common Italians clay bricks (dimensions equal to $65 \times 120 \times 250 \mathrm{~mm}^{3}$ ) and four $10 \mathrm{~mm}$ thick mortar joints, as shown in Figure 1. Strengthening is constituted by a common unidirectional carbon fiber textile $100 \mathrm{~mm}$ wide glued on the support by means of a thin layer of epoxy resin. No laboratory investigations were conducted in [29] to characterize the FRP system, so its geometric and mechanical properties (linear elastic assumptions) are assumed here equal to those declared by the manufacturer (E equal to $250 \mathrm{GPa}$, Poisson's ratio equal to 0.3 , thickness of $0.165 \mathrm{~mm}$ ). Due to the different surface curvatures, thickness of mortar joints varies; consequently, the bond length is variable from series to series. In Figure 1, the exact bond lengths for CAI (-a) and CBE (-b) specimens are depicted, whereas resultant bond lengths for all series are summarized in Table 1, with an indication of the reinforcement position, series labels and corresponding curvature radii of the pillar surface.

\begin{tabular}{cccc} 
Masonry prisms & Bond lengths [mm] & Reinforcement position & Curvature Radius [mm] \\
\hline CAE & 380 & Extrados & 1500 \\
\hline CAI & 330 & Intrados & 1500 \\
\hline CBE & 355 & Extrados & 3000 \\
\hline CBI & 330 & Intrados & 3000
\end{tabular}

Table 1: Bonded lengths and position used in the laboratory investigation.

Preliminary mechanical characterizations of bricks and mortar were performed in [29], useful to set properly elastic and inelastic numerical parameters for the proposed FE model. In particular, for bricks pull-off and uniaxial tensile and compression tests were carried out on small specimens cut from clay bricks.

For mortar, prisms were tested in three-point bending and uniaxial compression to characterize again tensile and compressive strength. The experimentally obtained mechanical properties (used also in the numerical simulations) are summarized in Table 2. The reader is referred to [29] for a detailed description of the 
laboratory tests performed and the results obtained. Here, it is worth noting that the numerical tensile strength assumed for mortar in the simulations is the experimental one divided by three, as commonly done in practice in this cases (see [29] for a discussion), to take into account that the experimental strength is conventionally evaluated from the ultimate bending moment assuming an elastic behavior of mortar.

\begin{tabular}{ccc} 
& Bricks & Mortar \\
Elastic Modulus [MPa] & 8712 & - \\
\hline Compressive strength [MPa] & 20.1 & 5.2 \\
\hline Tensile strength [MPa] & 2.5 & 1.9 \\
Table 2: Mechanical properties of the constituent materials.
\end{tabular}

The experimental set-up comprised a series of single lap shear tests on reinforced pillars, performed pulling the top edge of the FRP strip left un-bonded. In detail, each masonry pillar was constrained by two thick steel plates placed at its top and bottom bases. The given test apparatus was able to prevent any movement of the specimens during the tests as well as their rotation, as discussed in detail in [29]. During the laboratory investigation, a monotonically increased displacement was applied at the top edge of the dry carbon strip left unbounded. To this scope, a steel cylinder directly connected to the testing machine by means of a fork was used to transmit the vertical displacement to the masonry specimens. The dry carbon fiber strip was then glued to the steel cylinder after checking the proper alignment of the FRP textile and the absence of eccentricities. Vertical displacements were monitored in two different positions, namely at the loaded edge and at the beginning of the bond length. The first measure was obtained by means of two displacement transducers placed between the bottom of the load cell and the top steel plate. Doing this, the relative displacements between the testing machine and the top surface of the masonry pillars were monitored. Such measure of relative displacements can be the result of the initiation of different mechanisms, involving: (i) the elongation of the FRP strip, (ii) the presence of FRP-to-masonry debonding and (iii) the development of displacements due to a possible crushing of the brick in contact with the steel frame. Obviously, on the base of such a measure, it is not possible to distinguish one mechanism from another. In order to secure a more accurate insight into the developing mechanism, two $\Omega$ transducers were placed at the top edge of the bonded surface, allowing a more direct evaluation of the slip occurring between the upper end of the CFRP reinforcement and the masonry substrate. This second measure, which is expected to be more accurate (at least in the elastic phase), is crucial to remove from the global force-displacement curves obtained experimentally, spurious contributions consequent to possible rigid body motions of the specimen-machine system.

The final force-displacement curves obtained experimentally and used in the sequel to benchmark the performance of the FE approach proposed are summarized for each series in Figure 2.

Experimental evidences show that the curvature radius and the position of the reinforcement play an important role in the definition of the load carrying capacity, which varies considerably as a consequence of the positive or negative normal stresses arising at the FRP-support interface. 
Revised version, modifications highlighted in color YELLOW
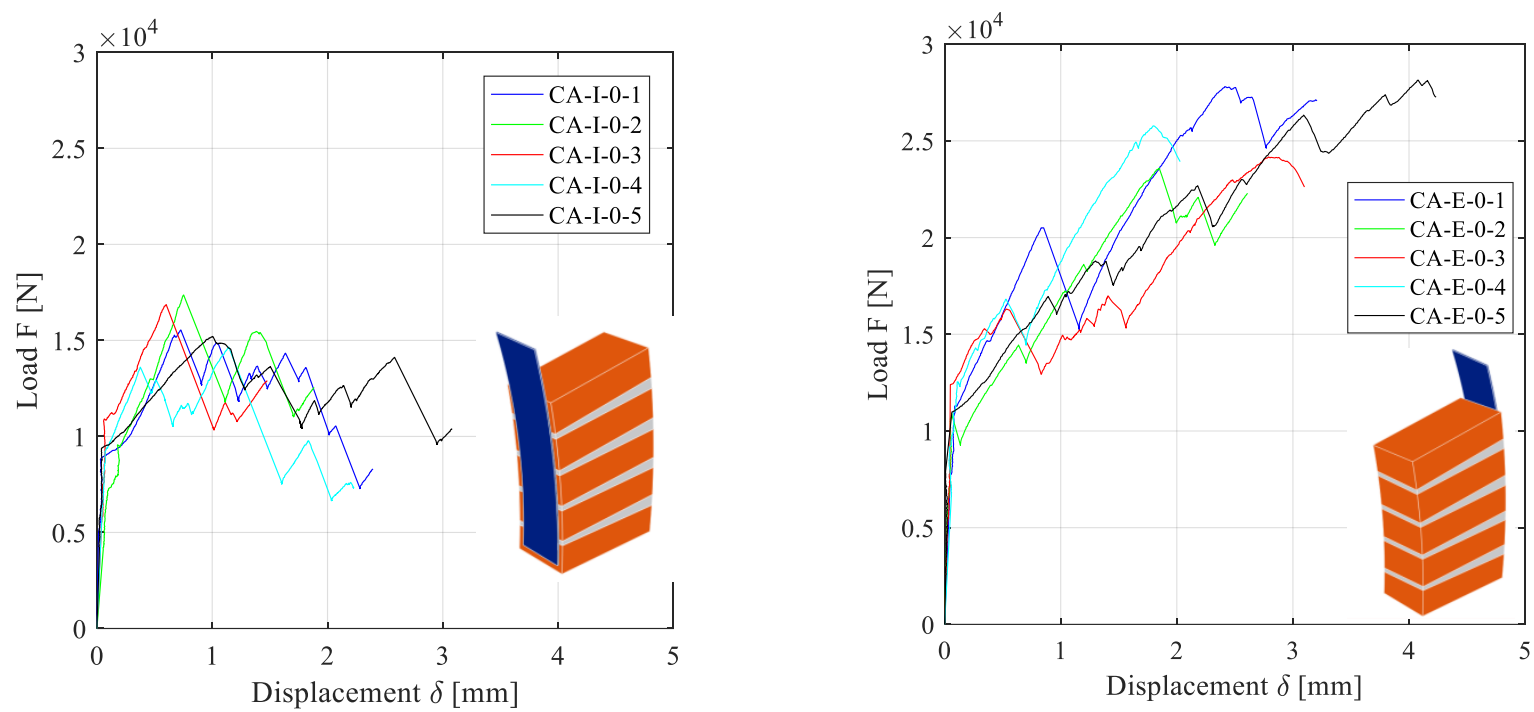

$-\mathrm{a}$
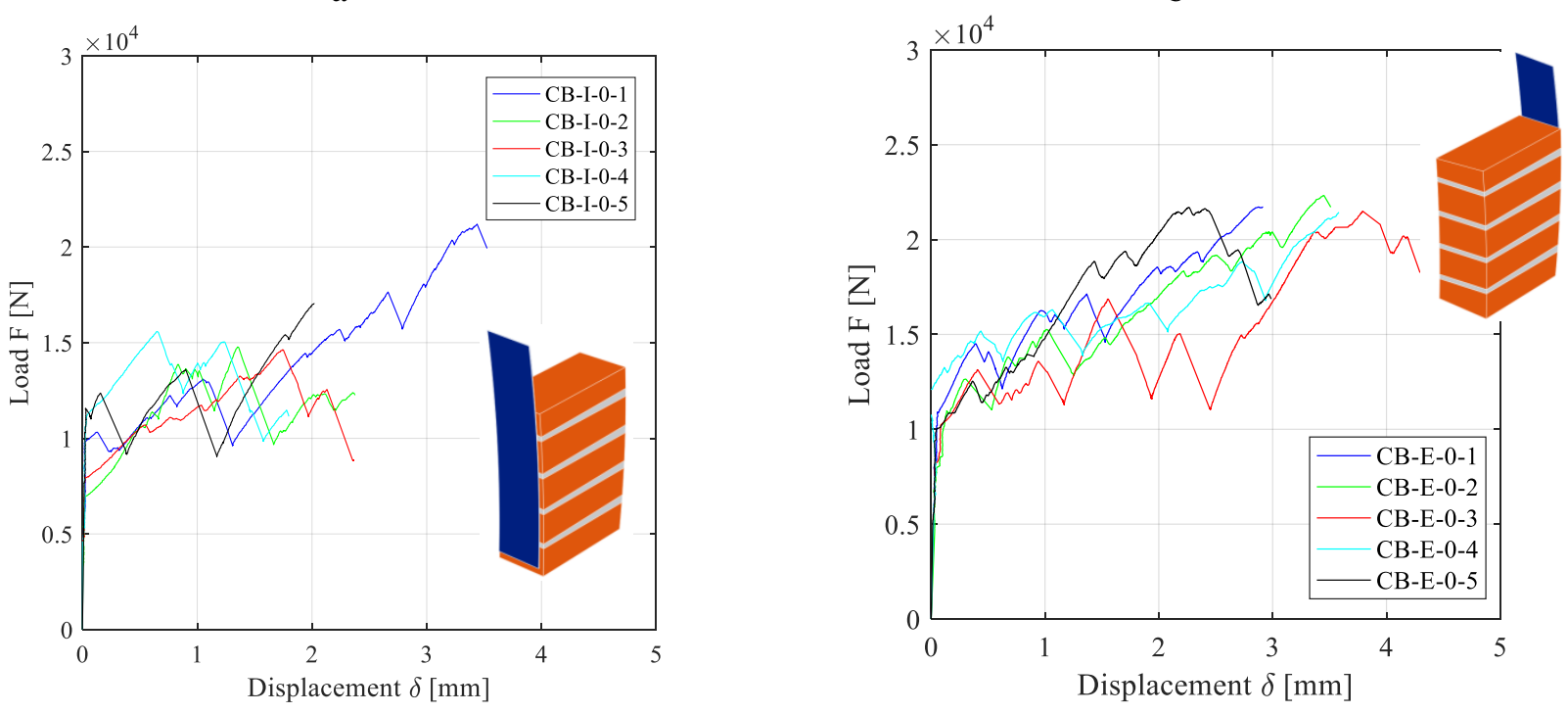

$-c$

$-d$

Figure 2: Single lap shear tests experimental results: CAI (-a), CAE (-b), CBI (-c) and CBE (-d) masonry prisms. 


\section{Numerical analyses}

In the present Section, an overview of the model proposed, as far as both the geometry and the mechanical properties of the constituent materials are concerned, is provided, with a final discussion of the results obtained. Emphasis is put on the role played by the tensile and compressive post peak behavior assumed for the bricks, whereas the role played by mortar is less important, simply because the mortar volume is limited and the contribution on the load carrying capacity (also because its strength is lower with respect to that of the brick) is limited.

\subsection{Abaqus model}

The numerical strategy herein proposed is a $2 \mathrm{D}$ plane strain heterogeneous micro-modelling, where the constituent materials (bricks, mortar joints and FRP reinforcement), are modelled separately. Elastic interfaces between FRP and support are also introduced, in order to properly capture the experimentally observed damage pattern of the support. All the simulations performed run under a commercial version of the FE code Abaqus [33]. Since the stress -transfer mechanism from FRP to masonry is typically brittle, with damage in tension and compression developing both superficially and relatively deep inside the volume, it is necessary to adopt quite refined discretizations not only near the application of the reinforcement, but also inside the bulk. In addition, the limited thickness of mortar joints when compared with the overall dimension of the pillar, requires a particularly refined discretization in correspondence of the joints (at least 7 FEs along their thickness are used). Two different FEs have been employed in the simulations: (ii) 4-noded plane strain quadrilateral elements (for bricks, mortar and FRP) with full integration formulation (bubble functions) and (ii) cohesive interfaces between FRP and substrate. The first type of elements relies into the category of the so called "incompatible" mode elements, which describe the bending behavior more accurately than traditional quadrilateral elements. To this scope, these FEs were equipped with more internal degrees of freedom, which allow the elimination of spurious shear stresses and the shear-locking phenomenon. From a computational point of view, they are slightly more expensive than their counterparts but less expensive than quadratic ones.

From a practical point of view, it is therefore convenient to maintain the same mesh size everywhere, avoiding in this way issues related to an excessive distortion of the elements. Meshes used for the simulations are depicted in Figure 3. As can be noted, meshes are quite refined, namely 12030 nodes and a total of 11757 FEs are used, of which 11631 4-noded plane strain FEs and 126 interfaces.

These latter elements are called in Abaqus "Cohesive" and are assumed elastic with uncoupled relationships between Mode I and II deformations. The elastic constitutive matrix is therefore $2 \times 2$ diagonal, linking the strain vector $\boldsymbol{\varepsilon}=\left[\begin{array}{ll}\varepsilon_{n n} & \varepsilon_{n t}\end{array}\right]^{T}$ with the interface stress vector $\mathbf{t}=\left[\begin{array}{ll}t & t_{n t}\end{array}\right]^{T}$ as follows

$$
\left[\begin{array}{c}
t_{n n} \\
t_{n t}
\end{array}\right]=\left[\begin{array}{cc}
E_{n n} & 0 \\
0 & E_{n t}
\end{array}\right]\left[\begin{array}{l}
\varepsilon_{n n} \\
\varepsilon_{n t}
\end{array}\right]
$$

Where $E$ is the elastic modulus and $n n$ and $n t$ denote the normal and tangential directions, respectively. 
$\varepsilon$ is the strain representing the ratio between the jump of displacement of corresponding nodes and the constitutive thickness of the interface, always assumed equal to $1 \mathrm{~mm}$ in the simulations for sake of simplicity. As a matter of fact, cohesive elements are usually characterized by two different thicknesses: a constitutive one and a geometrical one. The first one is related to the mechanical response of the interfaces. Indeed, the primary function of the constitutive thickness is to ensure that the nominal strains are equal to the relative separation displacements. The authors decided to adopt in the present simulations a layer of zerothickness interfaces between FRP and the masonry support because the actual thickness of such interface layer is hardly evaluable experimentally. Indeed, when the phenomenon involves two bonded surfaces where the adhesive layer is very thin or a fracture plane can be clearly identified, the adoption of a zero-thickness interface is preferable. In the FE software at hand, such kind of interfaces can be obtained using cohesive elements with a traction-separation response. In the proposed simulations, the application of a tractionseparation response ensures that the analyses are performed assuming a zero-thickness interface layer characterized by a unitary constitutive thickness, regardless the geometrical one. Being the numerical discretization enough refined and the shape of the FEs involved into the simulations regular, the authors decided to employ as geometrical thickness of the cohesive elements the same mesh size adopted for the other FEs, being fully reasonable from a practical point of view.

Simulations are carried out applying a monotonically increased displacement at the free edge of the CFRP strip left unbounded, up to the activation of a collapse mechanism. In agreement with the experimental setup described previously, steel plates are modelled by a combination of three series of rollers with different directions, as shown in Figure 4-b. It is interesting to notice that the top steel plate, which constraints almost all the top edge, is responsible for a diffusion of damage inside the masonry pillar limited to a superficial layer of few mm near the FRP. This experimental outcome is properly modelled, as already pointed out, thanks to the utilization of an elastic interface layer placed between the FRP and the support, see Figure 4-b.

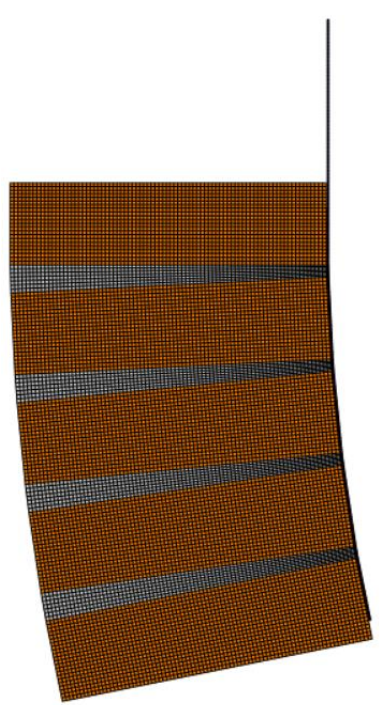

$-\mathrm{a}$

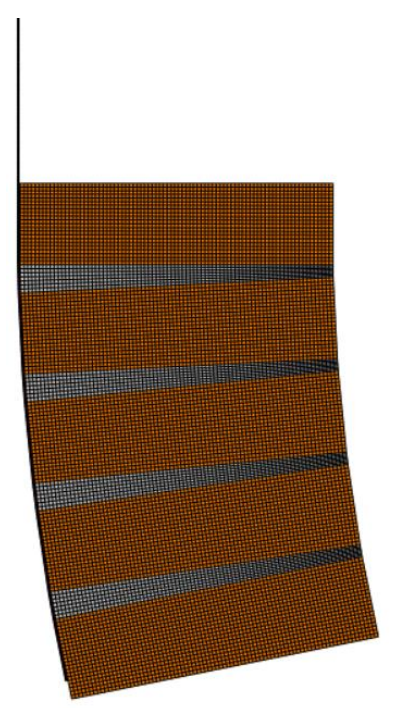

$-\mathrm{b}$

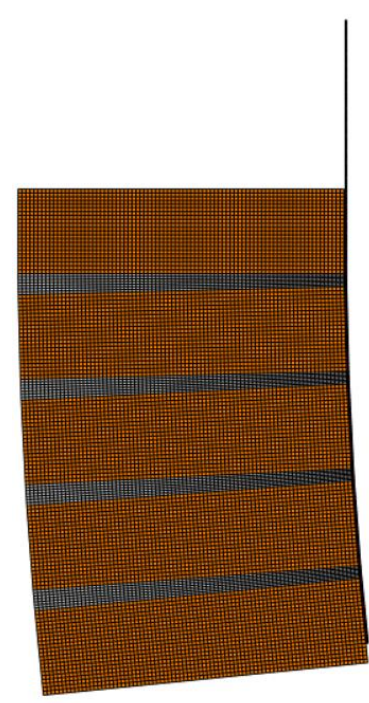

$-c$

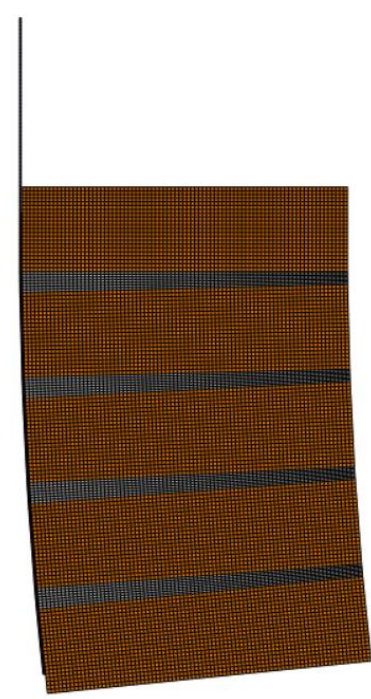

$-\mathrm{d}$

Figure 3: Discretization adopted for CAI (-a), CAE (-b), CBI (-c) and CBE (-d). 


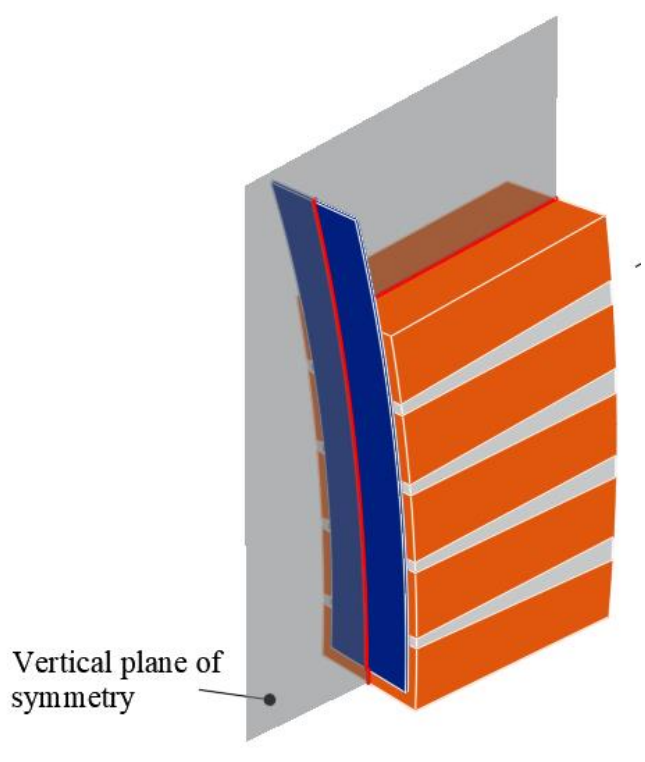

$-\mathrm{a}$

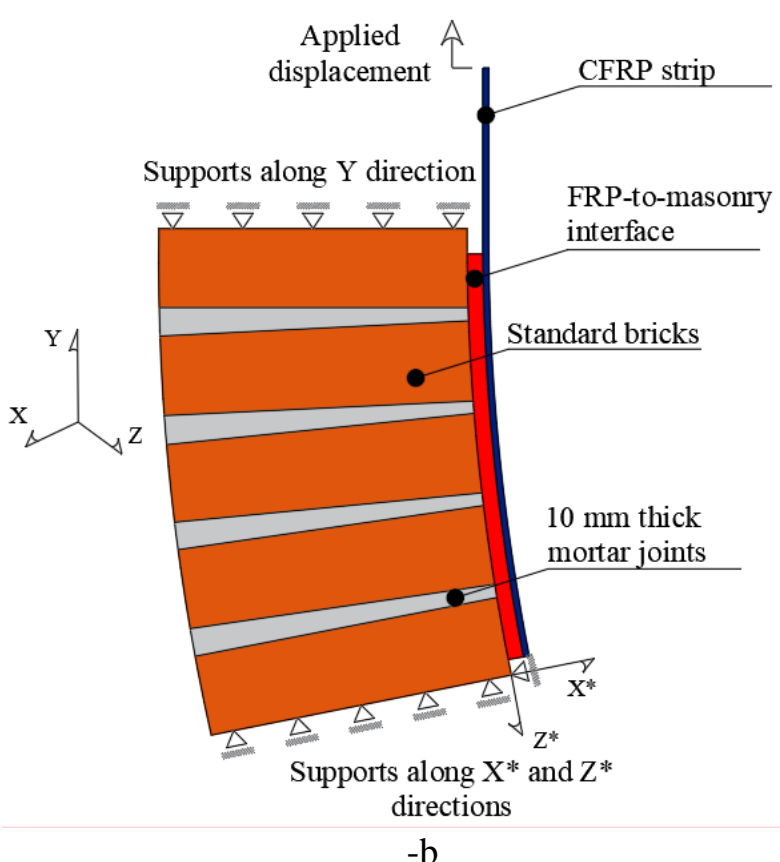

$-b$

Figure 4: CA curved specimens: modelling assumptions (-a), restraints adopted in the models (-b).

It is interesting to point out that some similar heterogeneous approaches, although with a different level of sophistication, have been already presented in the technical literature to describe the failure of FRP reinforced pillars [26][27]. However, in such studies, FRP was assumed as perfectly bonded to the substrate, whereas it is much more realistic to interpose, as done in the present study, between reinforcement and substrate an interface layer, whose mechanical parameters can be obtained resorting to suggestions provided by existing reference legislation (e.g. CNR DT 200 [17]). Following such recommendations, both the shear elastic stiffness and eventually the peak strength (not considered here because the support is assumed as elasto-damaging) can be easily estimated through the knowledge of constituent materials mechanical properties.

\subsection{Mechanical properties of the constituent materials}

As previously pointed out, the heterogeneous approach proposed requires a separate characterization of the single constituent materials, namely bricks, mortar, FRP and FRP-support interface. The following issues must be pointed out: (i) the most important parameter governing debonding load is brick tensile and compressive strength, (ii) FRP-to-masonry interface is assumed to play a crucial role only in terms of specimens deformability, also because here assumed elastic. The calibration of the mechanical properties adopted in the proposed simulations is described in the present Section. The adopted elastic properties for bricks, mortar and FRP are summarized in Table 3. As can be noted, the authors generally used values derived from data obtained experimentally [29], exception made for FRP (in this case technical tables are used). 
Revised version, modifications highlighted in color YELLOW

\begin{tabular}{ccc} 
& $\begin{array}{c}\text { Elastic Modulus } \\
{[\text { MPa] }}\end{array}$ & $\begin{array}{c}\text { Poisson ratio } \\
{[-]}\end{array}$ \\
\hline Brick & 8712 & 0.1 \\
\hline Mortar & 2500 & 0.1 \\
\hline Carbon fiber & 240000 & - \\
\hline Table 3 Elastic properties of the constituent materials.
\end{tabular}

Stress-strain uniaxial relationships adopted for bricks and mortar in tension and compression are sketched in Figure 5 (subfigure $-\mathrm{a}$ refers to the compression behavior, whereas subfigure $-\mathrm{b}$ to the tensile behavior). Three sets of simulations are repeated, one with an approximate exponential softening for the constituent materials (Set 1), the second with a linear softening up to a full inability to carry stresses (Set 2) and the last (Set 3) calibrated on the experimental stress-strain curve obtained testing under mono-axial compression some brick cubes. Generally authors noted a quite relevant importance of the compression post-peak behavior assumed for the bricks (Set 3 exhibits larger fracture energy in compression), with a roughly independence of the obtained global behavior in terms of constitutive laws assumed in tension and a scarce role played by mortar joints, with little contribution consequent to the limited volume and the lower strength when compared with bricks. 

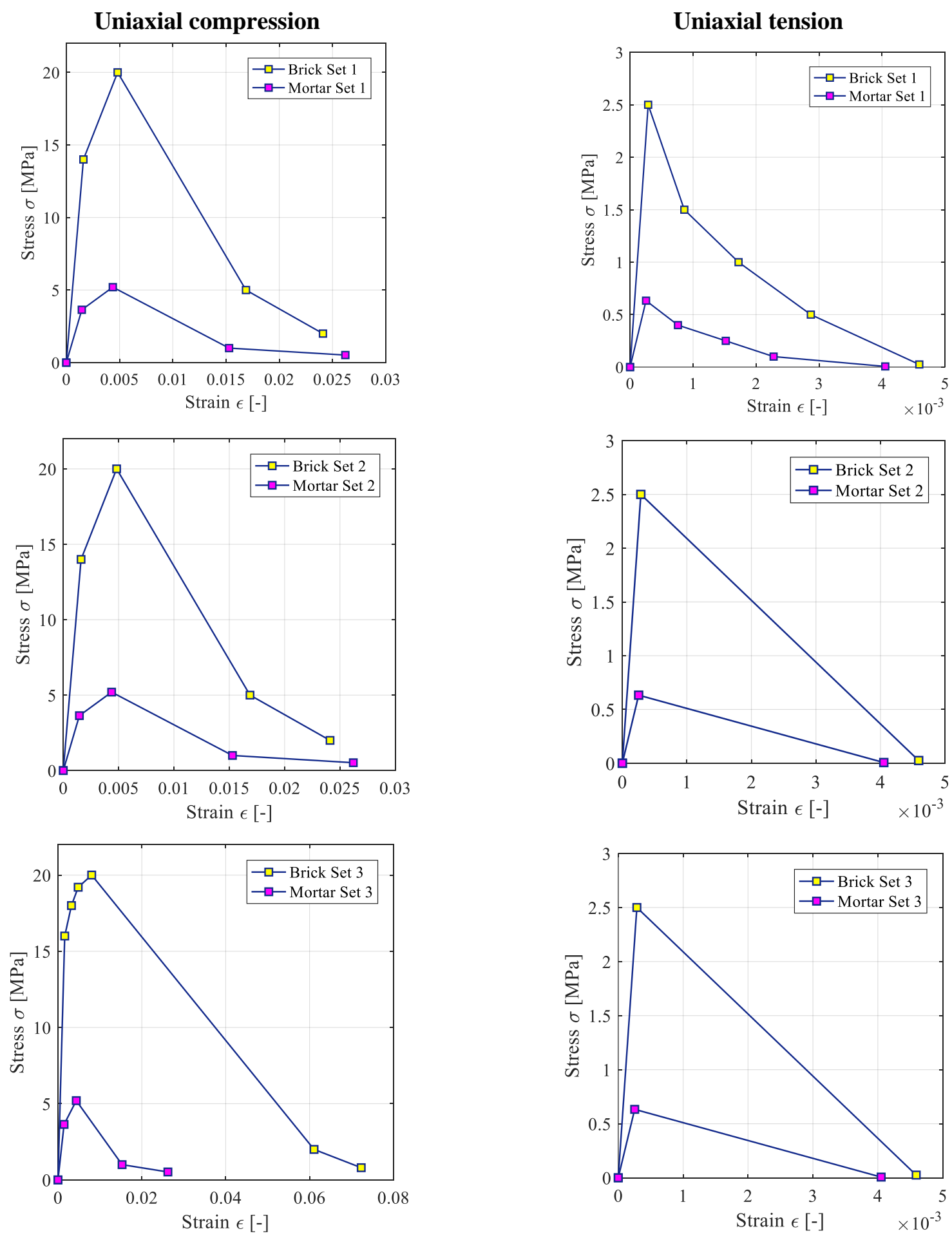

$-\mathrm{a}$

$-b$

Figure 5: Inelastic mechanical properties adopted for the constituent materials assuming uniaxial compression (-a) and tension (-b).

For bricks and mortar, a so called CDP (Concrete Damage Plasticity) model already implemented into the commercial code Abaqus [33] is utilized. CDP is a constitutive model which accounts for distinct damage parameters ( $\mathrm{dc}$ and $\mathrm{dt}$ ) in tension and compression, with possible softening and inelastic deformation due to 
damage and plasticity. To account for the multi-dimensional behavior, a modification of the Drucker-Prager failure criterion is assumed, which is characterized by a non circular failure surface in the deviatoric plane tuned by a numerical parameter called $\mathrm{Kc}$. If $\mathrm{Kc}=2 / 3$ the obtained Drucker-Prager failure surface approximates a Mohr-Coulomb one. The parameters employed in the CDP model are the following: $\mathrm{Kc}=$ $2 / 3$, dilation angle $=10^{\circ}$, viscosity parameter $=0.0001$ and ratio between the biaxial and uniaxial compression strength $=1.16$. In addition, to allow a better convergence, the tip of the conical Drucker-Prager strength domain is smoothed by means of an eccentricity parameter, which is assumed equal to 0.1 according to consolidated literature. Eccentricity represents in the $\mathrm{p}-\mathrm{q}$ plane the distance between the points of intersection with the $\mathrm{p}$-axis of the cone and the hyperbola, where $\mathrm{p}$ represents the pressure component of the stress matrix, while $\mathrm{q}$ is its deviatoric component.

The CDP non-linear model adopted is particularly suited to describe compressive crushing phenomena as well as tensile cracking failures in brittle or quasi-brittle materials. It has been initially developed to analyze non-linearities in concrete materials, but recently it has been successfully used to simulate masonries subjected to a variety of different loading conditions [34]. By user definition, in the present simulations, after a damage of the material equal to $90 \%(\mathrm{dt}=\mathrm{dc}=90 \%)$ tensile and compressive stresses are kept constant and almost equal to zero.

As already pointed out, the FRP strip are assumed elastic and applied to the masonry support interposing a single layer of zero-thickness interfaces. Interfaces are supposed to behave elastically without coupling between the tangential and normal modes. The FRP strengthened pillars are then loaded imposing a monotonically increased displacement at the top strip edge left unbounded. Mechanical properties of the carbon strip are assumed equal to those declared by the manufacturer since no laboratory investigations have been performed to characterize this material.

More difficult is the characterization of the interface, because its mechanical properties turn out to be crucial for a proper reproduction of the experimental stiffness exhibited by the reinforced specimens. In the numerical model, such data are kept in agreement with indications provided by the Italian code, where reliable formulas validated by a huge amount of experimentation ad hoc performed are put at disposal. A summary of the mechanical and geometrical parameters involved into the calculations is provided in Table 4 . Values identified by an asterisk * have been provided by the manufacturer, whereas those identified by a double asterisk ** have been identified by the authors by means of indirect consolidated formulas. The remaining mechanical properties are set in agreement with experimental results, exception made for all the shear elastic moduli, which have been calculated assuming an isotropic behavior for the constituent materials.

It is finally interesting to notice that, despite the fact that the interface between FRP and support is assumed elastic, it has obviously an influence in the propagation of damage inside masonry. As confirmed by the laboratory investigation, the failures of the masonry pillars studied in the present work were mostly due to 
the propagation of cracks involving few superficial $\mathrm{mm}$ of the masonry supports. This finding is also confirmed by several studies in literature. In single lap shear test, such crack propagation depth is usually related to boundary conditions, mechanical properties of mortar and bricks, but also to the presence of a soft elastic interface. For perfectly bonded FE models, indeed, damage spreads much deeper inside the bulk, as shown in [26]-[28]. Finally, also the position of the top steel plate in the experimental investigation tends to limit and concentrate damage near the skin on the pillar.

\begin{tabular}{|c|c|c|c|c|c|}
\hline $\mathrm{E}_{\mathrm{f}} *$ & $\begin{array}{c}\text { Carbon fiber Elastic modulus } \\
{[\mathrm{MPa}]}\end{array}$ & 240000 & $\mathrm{E}_{\mathrm{m}}$ & Elastic modulus of the block [MPa] & 8712 \\
\hline $\mathrm{t}_{\mathrm{f}} *$ & Fiber thickness [mm] & 0.165 & $v_{m} * *$ & Poisson ratio of the block [-] & 0.1 \\
\hline$b_{f}$ & Carbon fiber width [mm] & 100 & $\mathrm{G}_{\mathrm{m}}$ & Shear modulus of the block [MPa] & 3960 \\
\hline $\mathrm{E}_{\mathrm{a}} *$ & $\begin{array}{l}\text { Elastic modulus of the adhesive } \\
{[\mathrm{MPa}]}\end{array}$ & 2200 & $\mathrm{f}_{\mathrm{bm}}$ & $\begin{array}{l}\text { Brick average compressive strength } \\
{[\mathrm{MPa}]}\end{array}$ & 20.1 \\
\hline$v_{a}^{* *}$ & Poisson ratio of the adhesive [-] & 0.2 & $\mathrm{f}_{\mathrm{btm}}$ & Brick average tensile strength [MPa] & 2.5 \\
\hline $\mathrm{G}_{\mathrm{a}}$ & $\begin{array}{l}\text { Shear modulus of the adhesive } \\
{[\mathrm{MPa}]}\end{array}$ & 916.6 & $\mathrm{~b}$ & Block width [mm] & 120 \\
\hline
\end{tabular}

Table 4: Summary of the geometrical and mechanical parameters adopted to find the elastic stiffness of the cohesive elements.

Mechanical properties of the FRP-to-masonry cohesive interfaces, as calculated using the CNR DT 200, are synoptically shown in Table 5.

\begin{tabular}{lccc} 
ГFd & Fracture energy [N/mm] & $=\mathrm{k}_{\mathrm{b}} \cdot \mathrm{k}_{\mathrm{G}} \cdot \frac{\sqrt{\mathrm{f}_{\mathrm{bm}} \cdot \mathrm{f}_{\mathrm{btm}}}}{\mathrm{FC}}$ & 0.2383 \\
\hline fbd & Maximum tangential strength [MPa] & $=2 \cdot \frac{\Gamma_{\mathrm{Fd}}}{\mathrm{s}_{\mathrm{u}}}$ & 1.1915 \\
\hline le & Optimal debonding length [mm] & $=\frac{1}{\gamma_{\mathrm{Rd}} \cdot \mathrm{f}_{\mathrm{bd}}} \sqrt{\pi^{2} \cdot \mathrm{E}_{\mathrm{f}} \cdot \mathrm{t}_{\mathrm{f}} \cdot \Gamma_{\mathrm{Fd}} / 2}$ & 123.17 \\
\hline $\mathrm{Kt}$ & Tangential stiffness of the initial elastic branch & $=\frac{c_{1}}{\frac{t_{a}}{G_{a}}+\frac{t_{m}}{G_{m}}}$ & 106.22 \\
\hline $\mathrm{Kn}$ & Normal stiffness of the initial elastic branch $\left[\mathrm{N} / \mathrm{mm}^{3}\right]$ &
\end{tabular}

Table 5: Mechanical properties of the cohesive interface found using CNR DT $200\left(\mathrm{k}_{\mathrm{b}}=1.0871, \mathrm{k}_{\mathrm{G}}=0.031\right.$,

$$
\left.\mathrm{FC}=1, \mathrm{c}_{1}=0.5\right)
$$

\subsection{Numerical results}

In this Section, the numerical results obtained analyzing the four curved masonry pillars experimentally tested in [29] by means of the heterogeneous numerical approach previously described are discussed and compared with experimental evidences. As already pointed out, three series of analyses identified as Set 1-3 according to Figure 5 are performed. As far as the performance of the numerical models is concerned, it is worth noting that global comparisons with experimental data are provided, namely all simulations results are 
compared with experimental evidences monitoring the vertical displacements in a control point placed at the beginning of the bonded FRP, as shown in Figure 6, versus vertical reaction force applied.
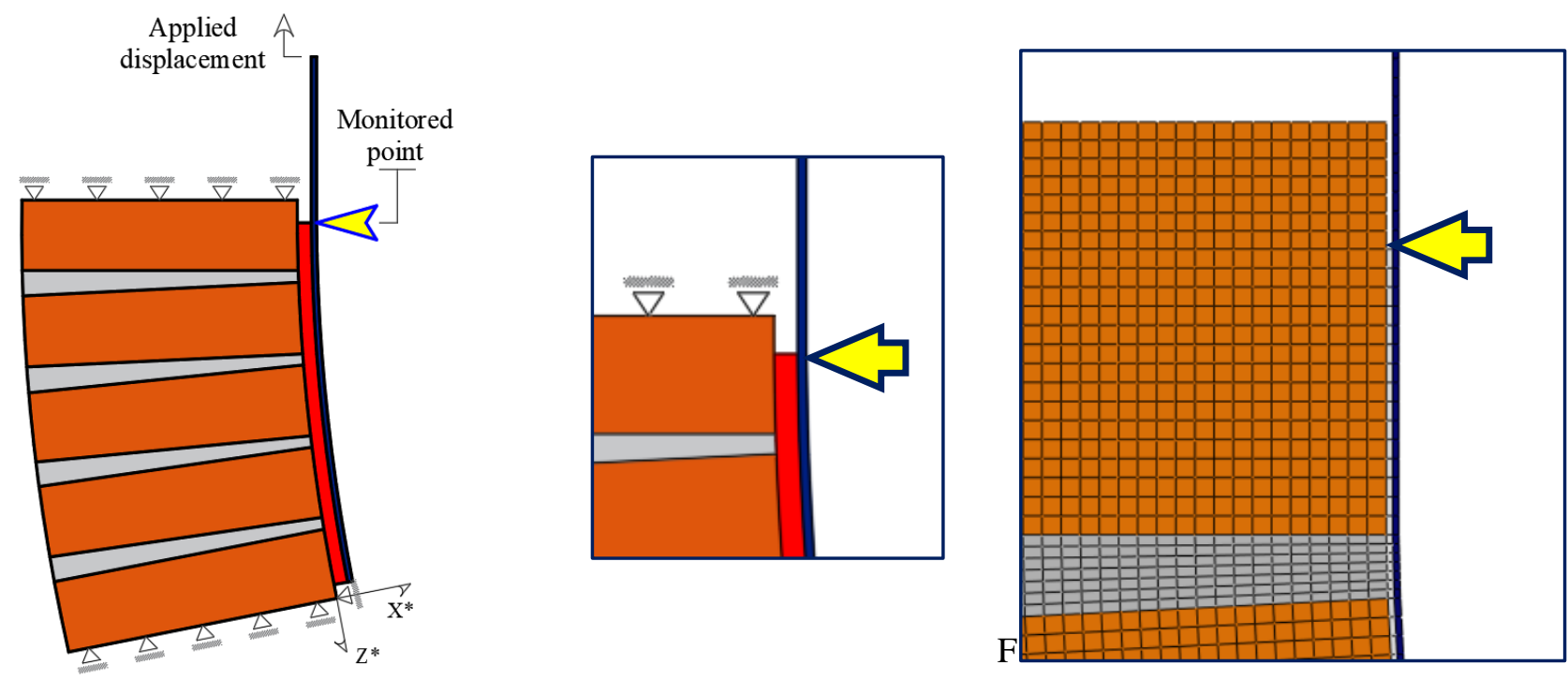

Figure 6: Schematic representation of the point assumed to control the numerical analyses.

The first results discussed refer to CA series. Global force-displacement numerical results are compared with experimental ones in Figure 7-a and Figure 8-a respectively for intrados and extrados reinforcements (i.e. CAI and CAE results). As can be noted, both FE models are able to accurately capture the first elastic behavior as well as the peak collapse loads.

\begin{tabular}{ccc} 
Description & Stiffness values & Units \\
\hline Finite Element Model CAI & $\mathbf{1 6 9 2 8 0}$ & $\mathbf{N} / \mathbf{m m}$ \\
\hline Max value (CAI 1) & 202640 & $\mathrm{~N} / \mathrm{mm}$ \\
Min value (CAI 2) & 78045 & $\mathrm{~N} / \mathrm{mm}$ \\
\hline Average value CAI & $\mathbf{1 4 7 0 8 6}$ & $\mathbf{N} / \mathbf{m m}$ \\
\hline
\end{tabular}

Table 6 CAI masonry pillars: experimental and numerical elastic stiffnesses.

A comparison between the elastic stiffnesses found numerically and those obtained in the experimental investigation is reported in Table 6 and Table 7, respectively for CAI and CAE specimens. As can be noted, the numerical stiffnesses differ from the mean values obtained experimentally of $-20 \%$ and $10 \%$, respectively. Although such difference is not negligible, it is worth mentioning that both the FE predictions result inside the experimental envelopes. Moreover, such an outcome is partially justified by the high scatter found experimentally. Almost the same scatter is obtained for the peak collapse loads. From an experimental point of view, the delamination of the FRP strips is characterized by an initial linear elastic phase, where the reinforcement is fully bonded to the surface, after which the FRP starts to debond and the load follows an oscillating trend. For all CAI specimens, such oscillation occurs around a constant value until failure. On the contrary, when the reinforcement is placed at the extrados, the load oscillates around a load linearly increasing with the displacement, up to a full debonding. Tensile damages spreading on pillars bulk during 
the analyses (points from A to D shown in Figure 7-b and Figure 8-b) are depicted in Figure 9 and Figure 10 for CAI and CAE respectively.

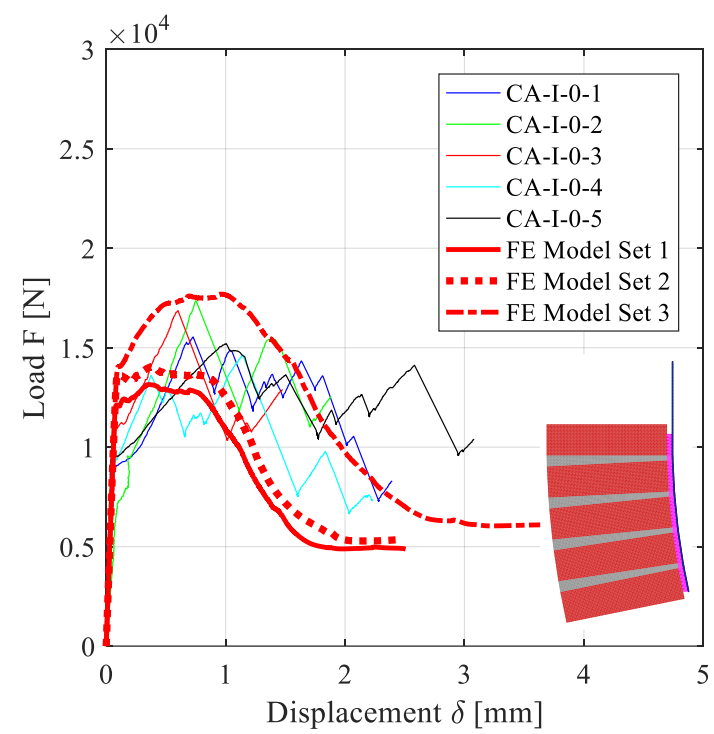

-a

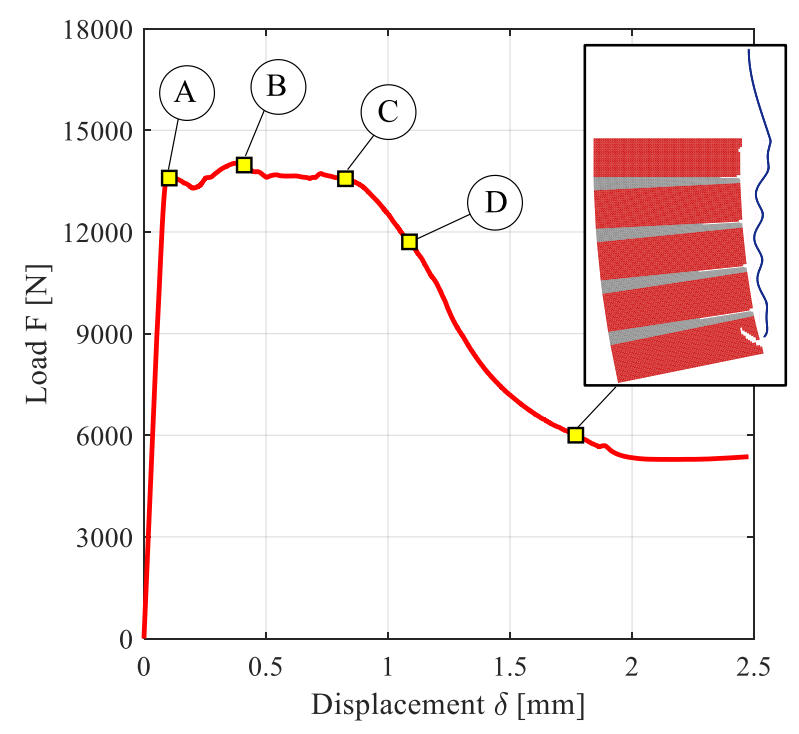

$-b$

Figure 7: CAI masonry pillars: comparison between experimental and numerical results (-a) and identification of time steps analyzed for the FE model Set 2 (-b).

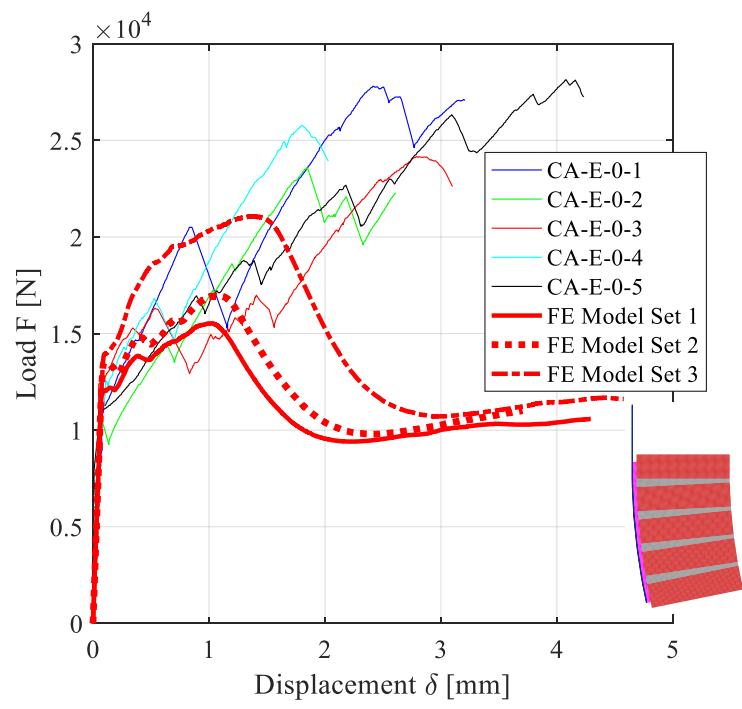

$-\mathrm{a}$

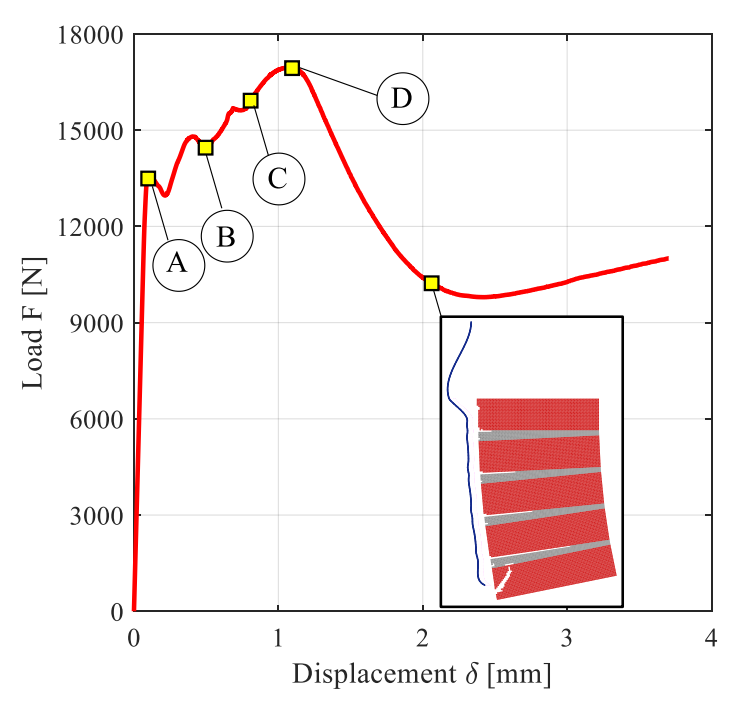

$-b$

Figure 8 CAE masonry pillars: comparison between experimental and numerical results $(-a)$ and identification of time steps analyzed for the FE model Set 2 (-b).

In agreement with experimental evidences, numerical simulations confirm that the load increases almost elastically until the FRP strip starts to detach (point A in Figure 9-a and -e and Figure 10-a and -e). From point $\mathrm{B}$ to point $\mathrm{C}$, a quick damage propagation is observed along the FRP-to-masonry interface for a depth equal to few $\mathrm{mm}$. 


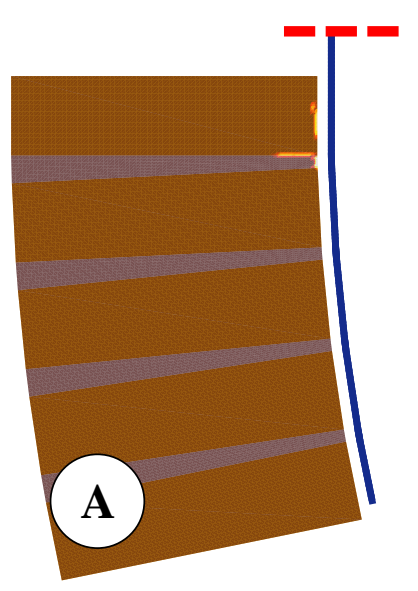

$-\mathrm{a}$

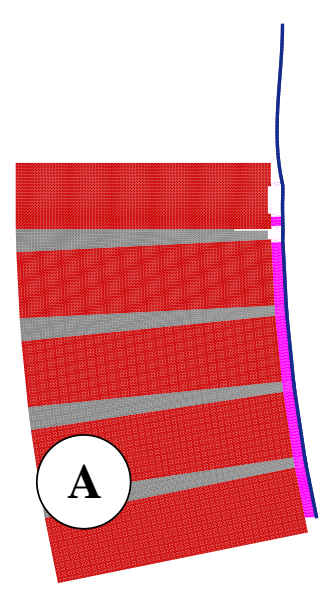

$-\mathrm{e}$

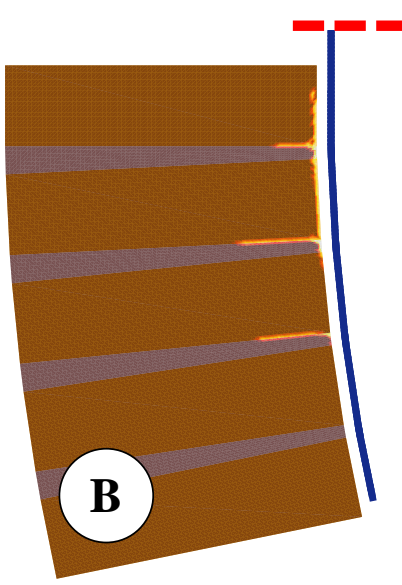

$-b$

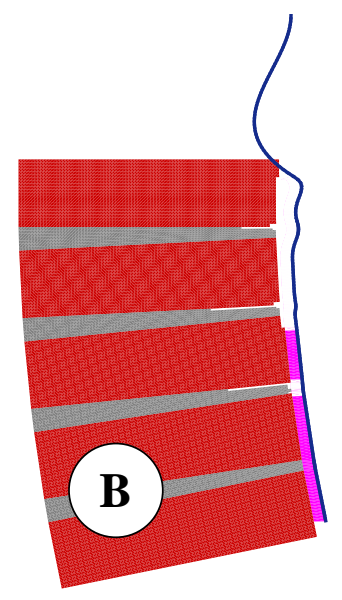

$-f$

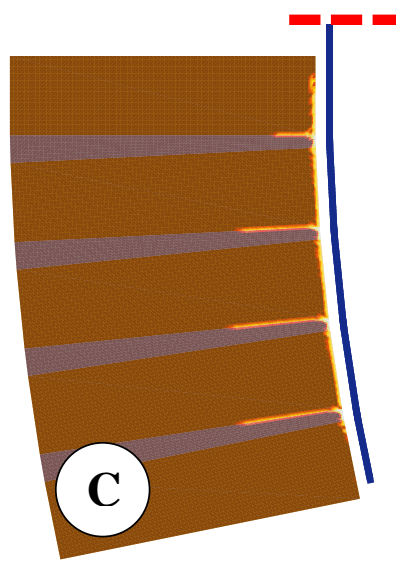

$-\mathrm{C}$

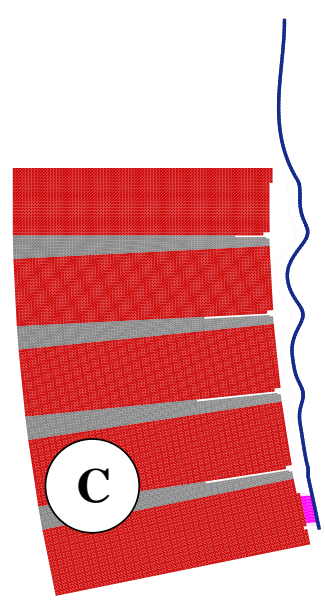

$-g$

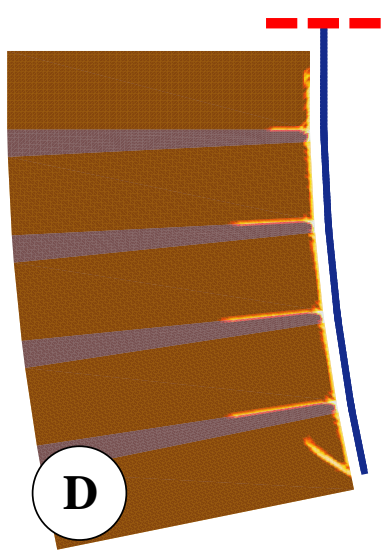

$-d$

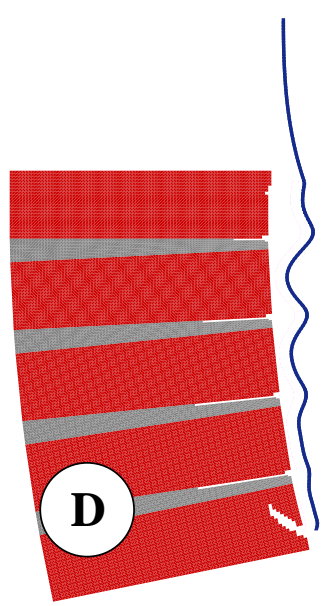

$-\mathrm{h}$

Figure 9 CAI masonry pillars.-a to -d: tensile damage maps obtained at different time steps. $-\mathrm{e}$ to $-\mathrm{h}$ : debonding mechanism at different time steps.

The softening phases (point $\mathrm{D}$ in Figure 9-d and $-\mathrm{h}$ and Figure 10-d and $-\mathrm{h}$ ) take place when the strengthening fully debonds from the support. Finally, in both models a post-peak residual strength is found, which corresponds to the resistance reserve in compression after that bricks crushing occurs. Such hypothesis had a twofold influence on the global behavior of the specimens. Indeed, the Concrete Damage Plasticity model allows defining a maximum inelastic strain which correspond to the $90 \%$ of degradation of the mechanical properties of the undamaged material. After that point, the tensile strength is kept constant even if the material is continuously loaded. Moreover, the FEs fully damaged cannot be removed from the analyses once they reach the maximum inelastic strain, as instead happens when dealing with inelastic cohesive elements.

A further explanation of the collapse mechanisms can be found in Figure 9 and Figure 10 from -e to $-\mathrm{h}$, where damage in tension data are post-processed in Matlab [35] for CAI and CAE specimens, removing all those elements with a tensile damage greater than $90 \%$ and the FRP-support interfaces in contact with 
damaged elements (magnification factors of displacements along horizontal and vertical direction are different by purpose to enhance figure readability). Such representation is very effective to understand the propagation of cracks inside the bulk and the delamination of the FRP from the support. Furthermore, it is interesting to notice that the processing zone inside the pillar is limited to few $\mathrm{mm}$.

Finally, the images clearly show the evolution of the strip debonding, which starts from the loaded side and quickly propagates downwards, again consistently with the experimental results discussed in [29]

\begin{tabular}{ccc} 
Description & Stiffness values & Units \\
\hline Finite Element Model CAE & $\mathbf{1 6 8 3 1 0}$ & $\mathbf{N} / \mathbf{m m}$ \\
\hline Max value (CAE 5) & 256519 & $\mathrm{~N} / \mathrm{mm}$ \\
Min value (CAE 1) & 128082 & $\mathrm{~N} / \mathrm{mm}$ \\
\hline Average value CAE & $\mathbf{1 7 9 1 2 3}$ & $\mathbf{N} / \mathbf{m m}$ \\
\hline
\end{tabular}

Table 7: CAE masonry prisms: experimental and numerical elastic stiffnesses. 


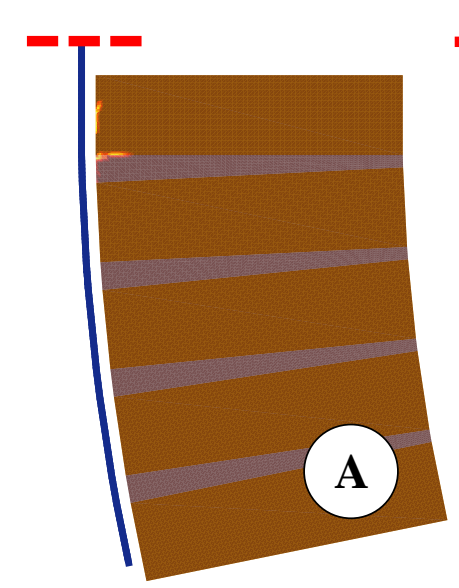

$-\mathrm{a}$

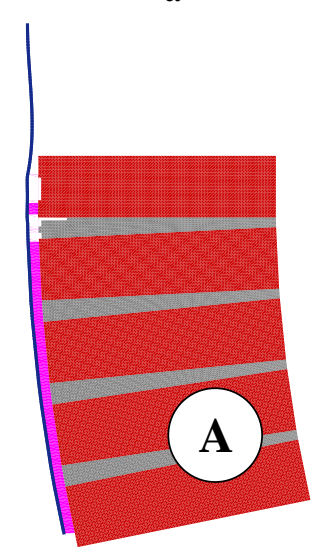

$-\mathrm{e}$

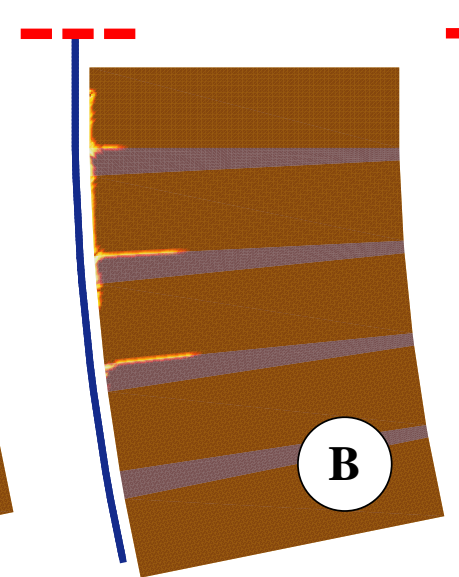

$-b$

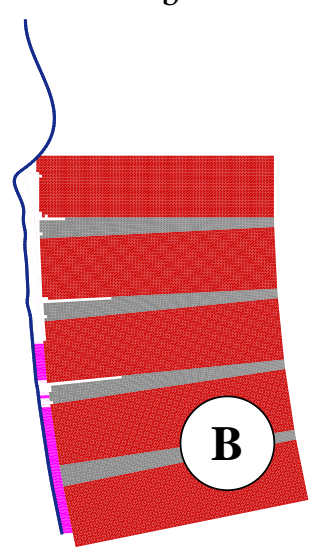

$-f$

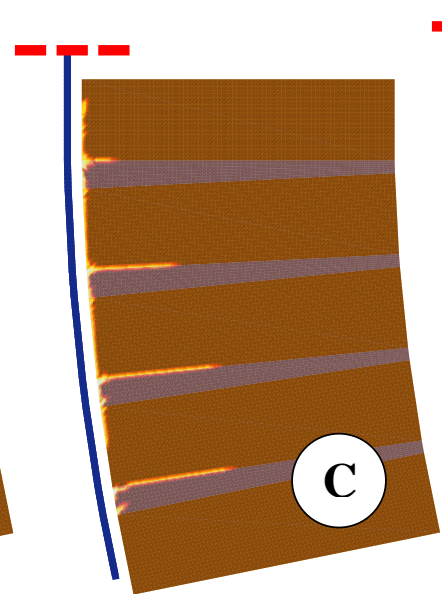

$-\mathrm{c}$

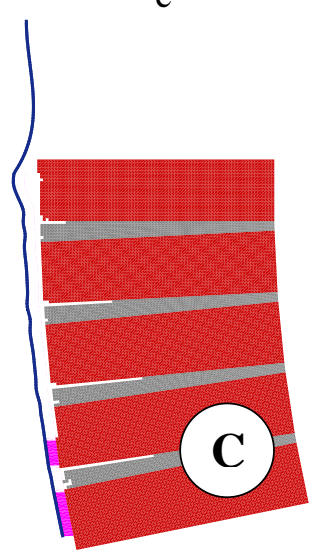

$-\mathrm{g}$

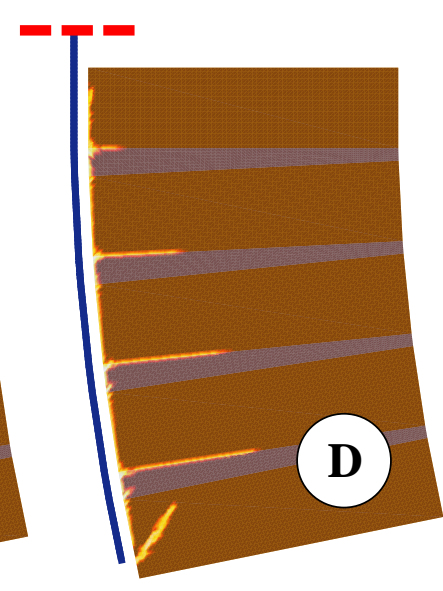

$-\mathrm{d}$

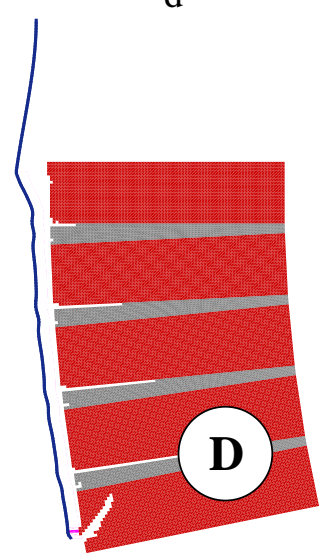

$-\mathrm{h}$

Figure 10: CAE masonry pillars: -a to $-\mathrm{d}$ : tensile damage maps obtained at different time steps. -e to $\mathrm{h}$ : debonding mechanism at different time steps.

Numerical load -displacement curves found for series CB are depicted in Figure 11 (CBE, extrados) and Figure 12 (CBI, intrados). 


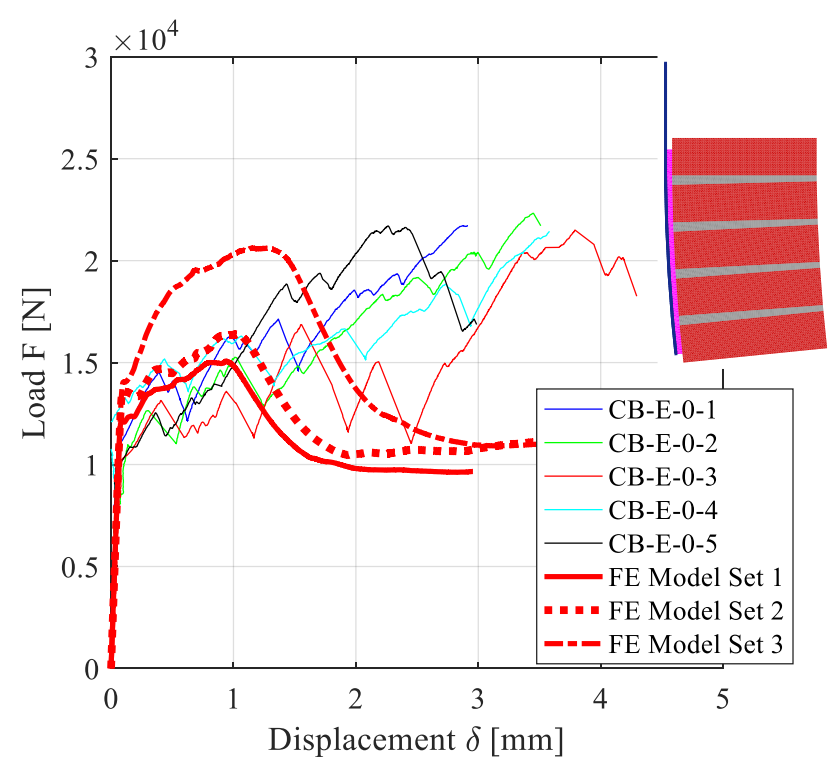

-a

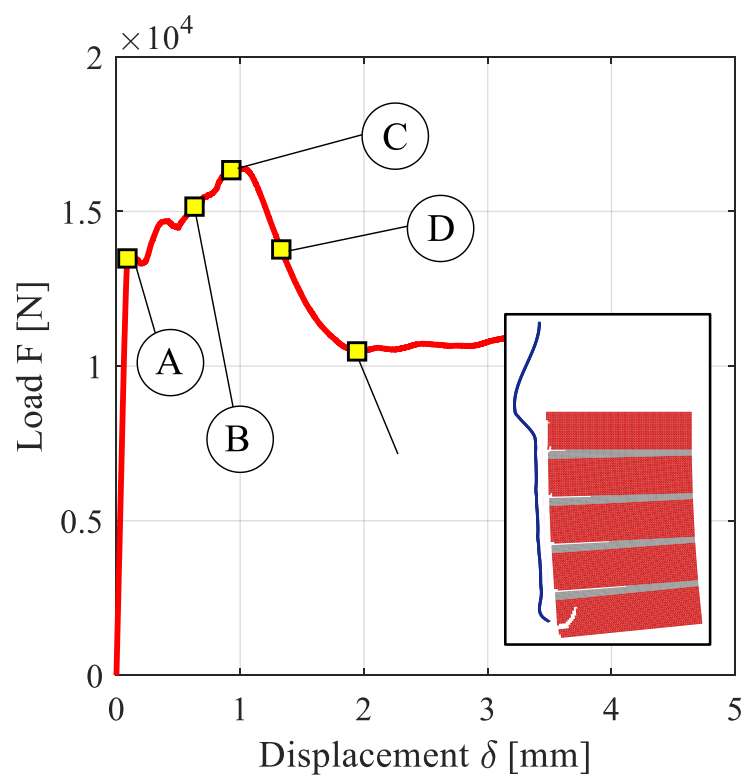

$-\mathrm{b}$

Figure 11 CBE masonry prisms: comparison between experimental and numerical results (-a) and identification of some meaningful points on the Set 2 numerical curve (-b).

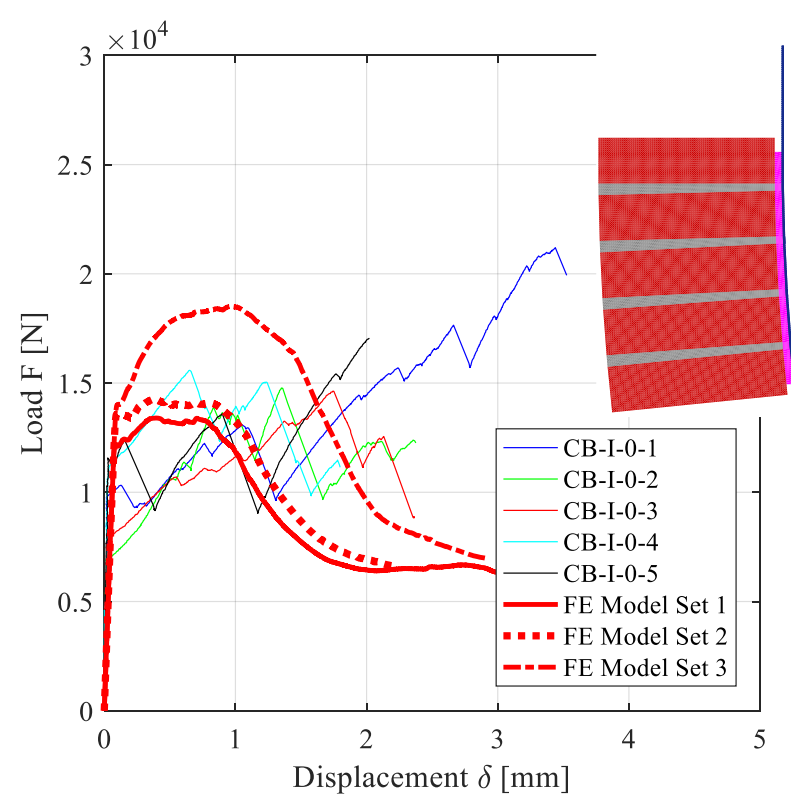

-a

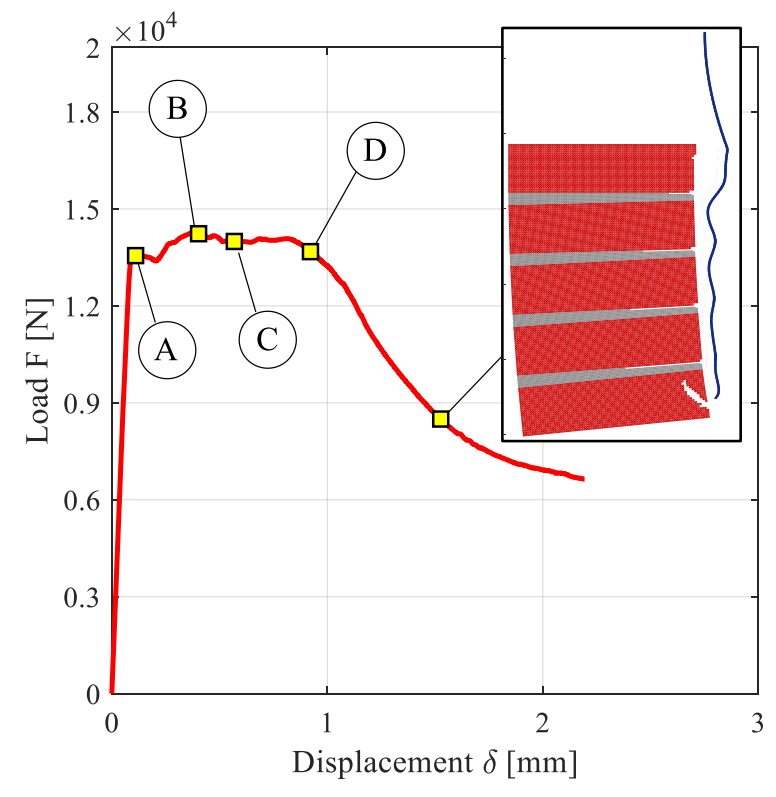

$-\mathrm{b}$

Figure 12 CBI masonry prisms: comparison between experimental and numerical results (-a) and identification of some meaningful points on the Set 2 numerical curve (-b).

For CBE the numerical model slightly underestimates the experimental peak load, whilst the initial elastic stiffness results again inside the experimental envelope. On the contrary, CBI numerical models appear more in agreement with experimental evidences almost everywhere. A summary of the stiffness values found in the experimental tests compared with the numerical one is reported for CBE in Table 8 and for CBI in Table 9 respectively. Unfortunately, when dealing with this latter set of tests, only one experimental measure was at disposal. The discrepancies observed at large displacements, with a softening behavior of the numerical 
model which is never observed in experimentation, may be explained by the relatively marked softening assumed in compression for bricks and mortar.

\begin{tabular}{ccc} 
Description & Stiffness values & Units \\
\hline Finite Element Model CBE & $\mathbf{2 2 0 6 7 0}$ & N/mm \\
\hline Min value (CBE 2) & 193588 & $\mathrm{~N} / \mathrm{mm}$ \\
Max value (CBE 1) & 247943 & $\mathrm{~N} / \mathrm{mm}$ \\
\hline Average CBE & $\mathbf{2 2 2 0 8 5}$ & $\mathbf{N} / \mathbf{m m}$ \\
\hline
\end{tabular}

Table 8: CBE masonry pillars: experimental and numerical elastic stiffnesses.

\begin{tabular}{ccc} 
Description & Stiffness values & Units \\
\hline Finite Element Model CBI & $\mathbf{1 6 9 5 0 0}$ & $\mathbf{N} / \mathbf{m m}$ \\
\hline CBI 3 & 396923 & $\mathrm{~N} / \mathrm{mm}$ \\
\hline Table 9: CBI masonry pillars: experimental and numerical elastic stiffnesses.
\end{tabular}




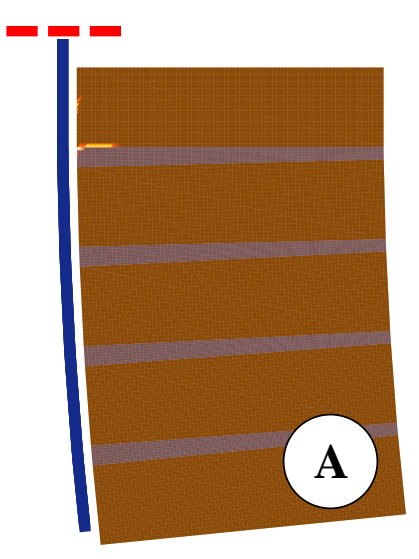

$-a$

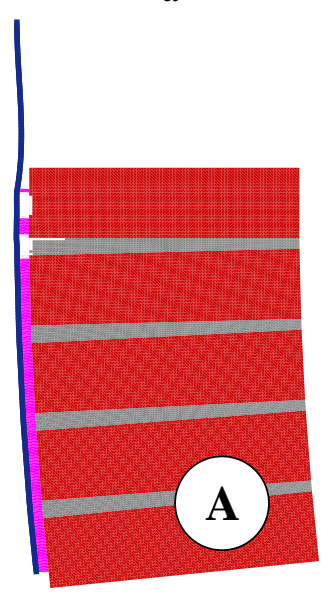

$-\mathrm{e}$

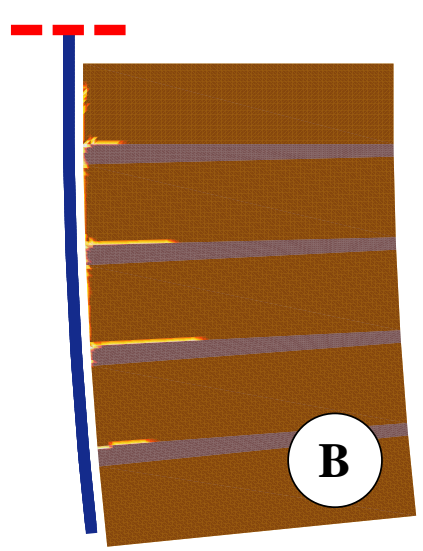

$-b$

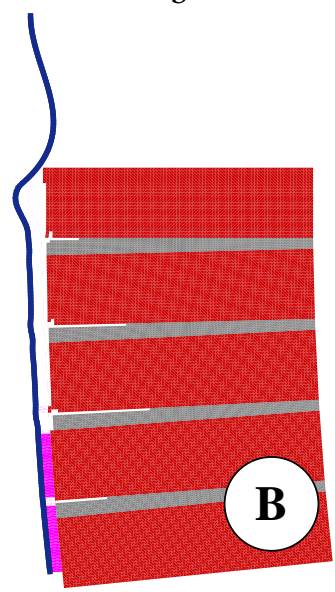

$-\mathrm{f}$

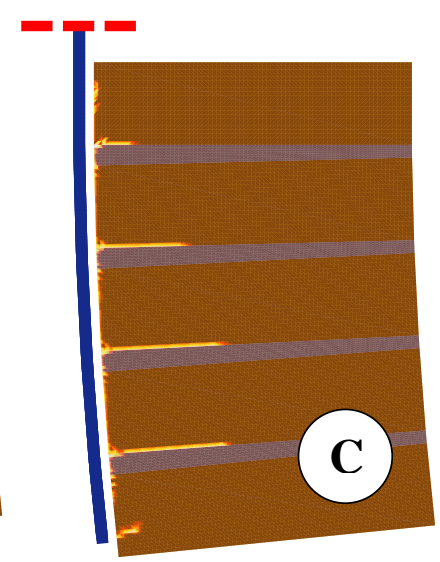

$-\mathrm{c}$

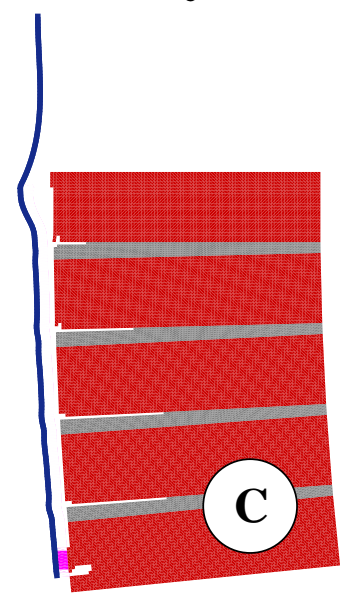

$-g$

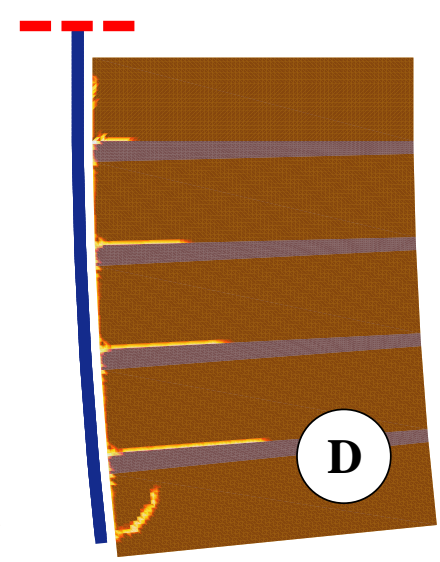

$-d$

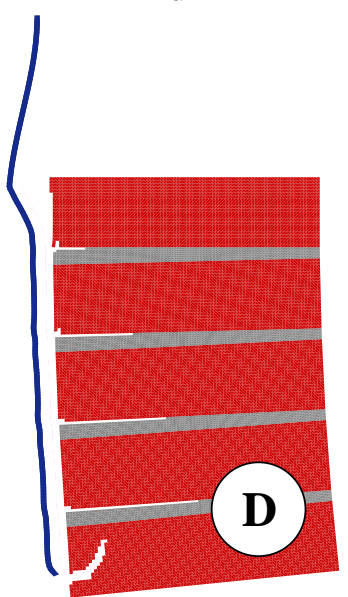

$-\mathrm{h}$

Figure 13: CBE masonry pillars. -a to -d: tensile damage maps obtained at different time steps. -e to $\mathrm{h}$ : debonding mechanism at different time steps.

Analogously to the previous series CA, the detachment of the FRP starts form the top brick close to the loaded edge (Figure 13-a and -e and Figure 14-a and -e), quickly propagating downwards. The numerical load trends seem to confirm the results obtained for CA specimens. Indeed, when the reinforcement is applied at the extrados of the curved pillar, the load after the elastic phase seems to follow a roughly linear increasing trend until the complete debonding. On the contrary, the intrados strengthened specimens are characterized by a fairly constant load during the debonding propagation. Such behavior is a consequence of the presence of tensile or compressive normal stresses acting at the FRP-to-support interface. Indeed, comparing CAE and CBE force-displacement curves, it is clear that after the elastic phase almost all the specimens exhibit an increase of the debonding load, which is related to a Mohr-Coulomb strength of the interface. Such increase, not observed in CAI and CBI pillars, can be justified therefore by the existence of compressive normal stresses which improve the shear bond performance of the FRP strengthening, according to a Mohr-Coulomb inelastic relationship between normal and tangential stresses. Macroscopically, it is observed that the ultimate force required to fully detach the reinforcement grows. 


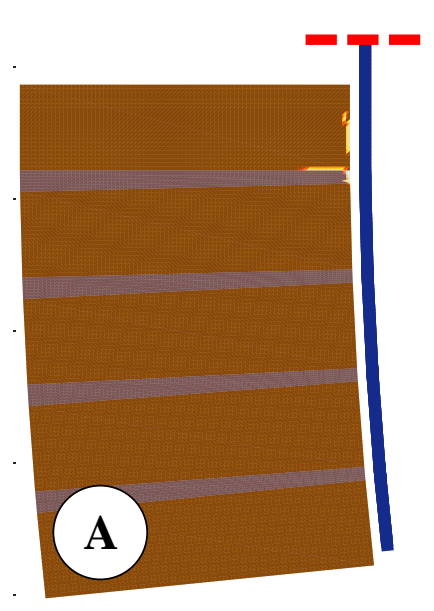

$-\mathrm{a}$

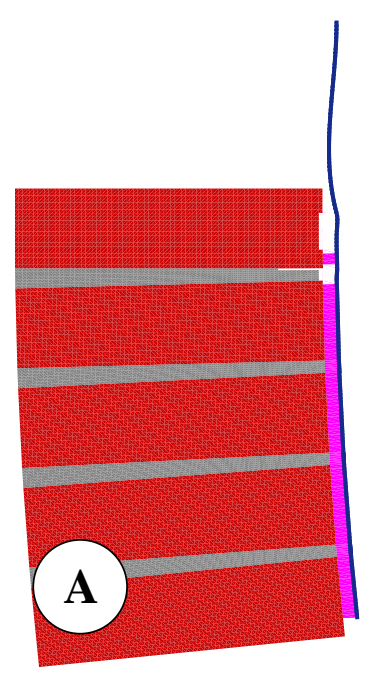

$-\mathrm{e}$

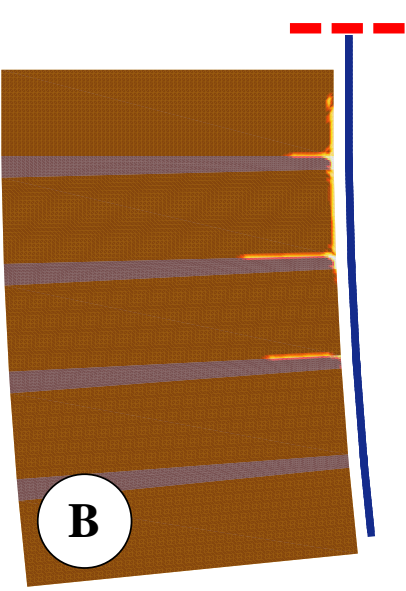

$-b$

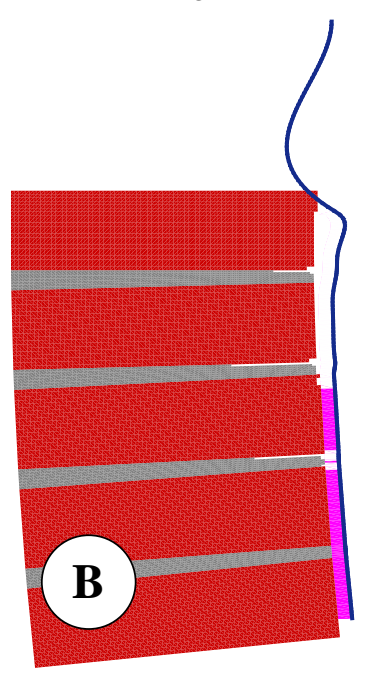

$-f$

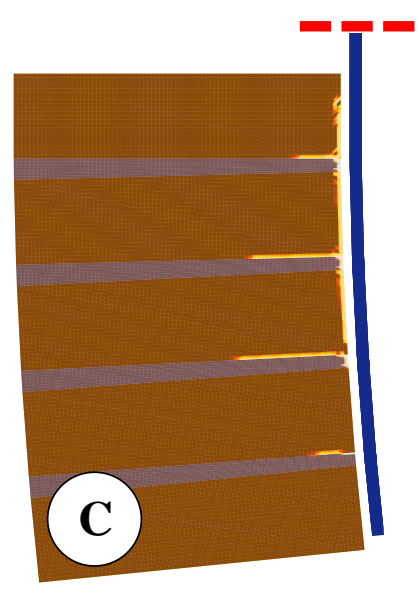

$-\mathrm{C}$

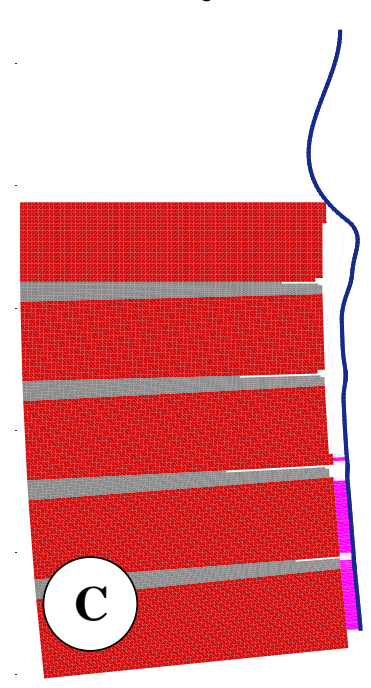

$-\mathrm{g}$

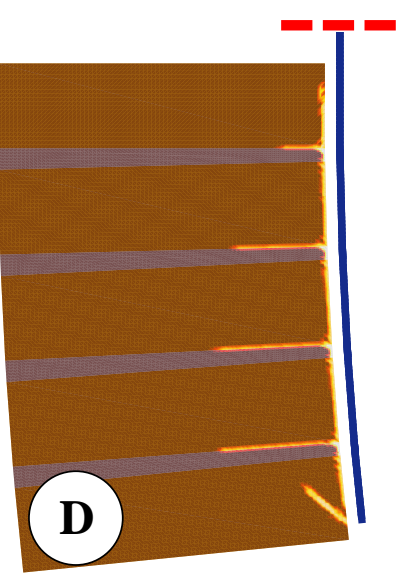

$-d$

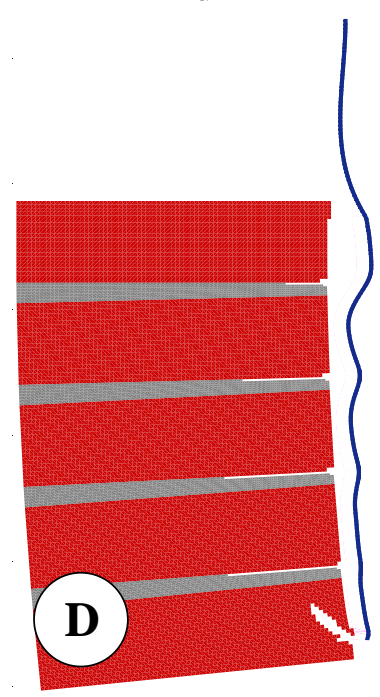

$-\mathrm{h}$

Figure 14: CBI masonry pillars. -a to $-\mathrm{d}$ : tensile damage maps obtained at different time steps. $-\mathrm{e}$ to $\mathrm{h}$ : debonding mechanism at different time steps.

Table 10 synoptically compares the numerical peak loads obtained for the different cases analyzed, whereas in Figure 15 the percentage increases/decreases of the load carrying capacity with respect to CBE specimens are shown using histograms. As can be noted, the FE models consistently reproduce the positive or negative effects induced by the curvature of the surface. As a matter of fact, the minimum peak load is obtained in the masonry pillars with the lowest curvature radius (i.e. $1500 \mathrm{~mm}$ ) reinforced at the intrados. In this case, the concave geometry of the support plays a detrimental role, with the presence of tensile normal stresses reducing the ultimate load carrying capacity. Due to the presence of such stresses the force needed to detach the FRP strip results lower with respect to the flat configuration. As expected, the maximum positive effect can be found with a curvature radius of $1500 \mathrm{~mm}$, but with the reinforcement placed at the extrados. Such situation is comparable to a convex geometry upon which the reinforcement is placed. In this specific case, the geometry of the support increases the bond performance of the FRP materials, thanks to the development of compressive normal stresses arising on the pillar at the FRP-to-masonry interface. As expected, the numerical models capture with sufficient accuracy such behavior. Indeed, the maximum collapse load is 
found in CAE simulations. When the curvature of the strengthened masonry decreases, the positive and negative effects due to the geometry of the supports are mitigated. When the curvature is negligible (i.e. curvature radius $\rightarrow \infty$ ), that corresponds to a flat surface where the geometry of the support clearly does not influence the performance of the FRP strengthening.

\begin{tabular}{lcccc} 
Collapse load [N] & CAE & CAI & CBE & CBI \\
\hline FE Models Set 1 & 15531 & 13152 & 15077 & 13398 \\
\hline FE Models Set 2 & 16944 & 14029 & 16382 & 14258 \\
\hline FE Models Set 3 & 21073 & 17692 & 20619 & 18503 \\
& Table 10: Summary of the collapse loads obtained with the FE models.
\end{tabular}

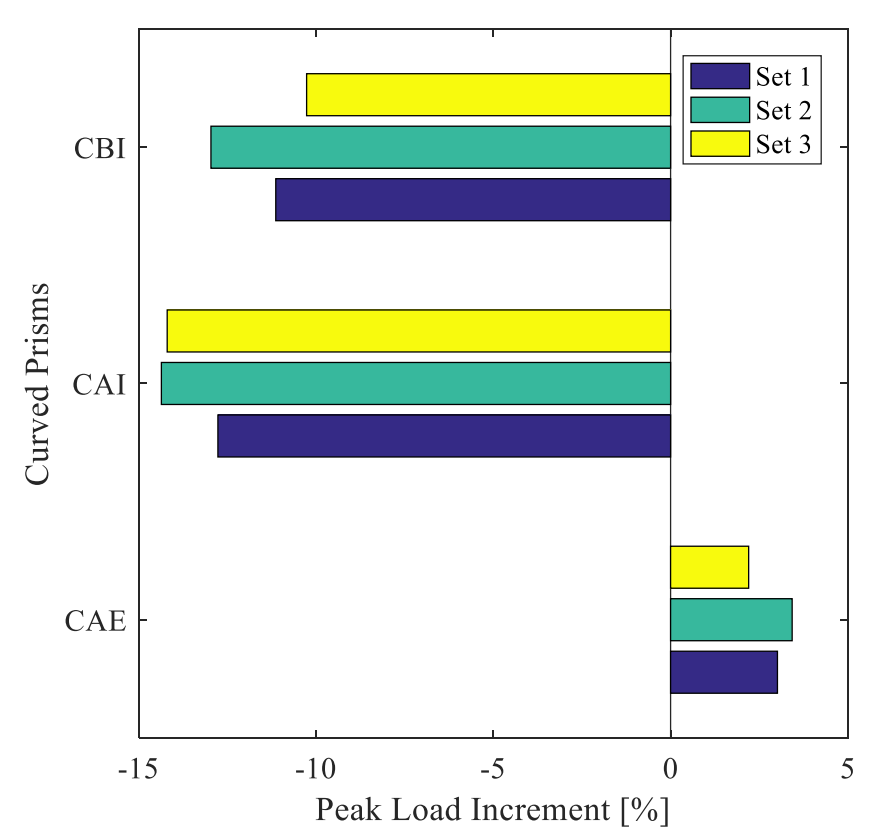

Figure 15: Peak load increments calculated for CAE, CAI and CBI prisms with respect to CBE specimens.

\section{Sensitivity analyses}

The numerical model proposed allows carrying out fast sensitivity analyses changing the curvature radii of the specimens. The goal is to provide fast predictions of the debonding behavior at different curvatures, without the need to perform costly experimental campaigns.

In the present Section, therefore, the same heterogeneous FE model used to fit experimental data is utilized under the same load conditions (single lap debonding) and the same mechanical properties of the materials, but changing the curvature of the bonded surface. In particular, FE simulations are repeated for the following positive (intrados reinforcement) and negative (extrados reinforcement) curvature radii: 500, 750, 1500, 3000 and $6000 \mathrm{~mm}$. It is worth noting that the last radius of curvature $(6000 \mathrm{~mm})$ is so large that the curvature effect is in practice almost totally lost and the specimen can be reasonably considered as flat (and hence results can be kept as reference to compare with). 
Load displacement curves obtained for the three different Sets of mechanical properties and curvature radii equal to 500, 750 and 6000 are depicted in Figure 16. The resultant crack patterns at failure (i.e. fully developed) for Set 3 mechanical properties are also reported for the sake of completeness. Similar outcomes are observed for Set $1 \& 2$. Cases with $\mathrm{R}=1500$ and 3000 are not reported because previously presented when comparing with experimentation.

From a detailed analysis of Figure 16, the following considerations can be drawn:

1) Brick fracture energy in tension does not affect too much the global behavior; as a matter of fact, the peak load increases slightly from Set 1 to Set 2, whereas the residual strength and the elastic behavior remain essentially unchanged. This is reasonable because the contribution on the global dissipation of energy in tension is much lower than that in compression.

2) A variation of brick fracture energy in compression, conversely, results into a quite evident change of the peak load. Such behavior can be justified by an interpretation of the crack pattern at failure, which involves a thickness of about 10-15 mm inside the pillar, with the processing zone working mainly in compression.

3) Peak load percentage increases/decreases with respect to the flat case are represented using histograms in Figure 17. There are some inversions with respect to Figure 16 where global loaddiagram curves are shown, because normalization is made against the flat case, but assuming consistently the same mechanical properties adopted for the curved specimens (for example peak loads obtained for Set 3 on curved pillars are normalized against peak load in the flat case assuming again for materials Set 3 data). In any case, the trend is pretty clear for all Sets, with an increase/decrease trend that can be assumed roughly hyperbolic.

4) Residual strength turns out to be roughly the same for the three Sets of mechanical properties adopted for bricks, clearly indicating that the full activation of a mechanism is independent from the post peak behavior assumed in compression for bricks. As a matter of fact, when the delamination process is fully developed, shear stress is the most important parameter contributing to the residual strength. Such stress component is defined in CDP by an elasto-plastic law, i.e. independently from the uniaxial compressive strength and the post peak behavior of the material. Being such strength the same for all Sets and linked to the tensile strength via a Mohr-Coulomb relationship, this explains the reason why the residual delamination force is quite insensitive to a variation of the post-peak parameters in compression.

5) Elastic upper limit appears remaining unaltered varying the curvature radius, as clearly shown in Figure 18. In agreement with intuition, indeed, in the elastic range normal and tangential stresses at the interface are uncoupled and the slight differences are related exclusively to a variation of the principal stresses direction on elements near the bonded surface consequent to the geometry variation. 
Finally, Figure 19 shows the peak loads obtained for the different curvature radii investigated. Three subfigures are reported, each one referred to a different Set of mechanical properties assumed for bricks, so that subfigure - a refers to Set 1, -b to Set 2 and -c to Set 3 respectively. On the horizontal axis, the curvature radius of the bonded surface is reported, whereas on the vertical axis the peak debonding force is represented. Apart the roughly hyperbolic behavior already pointed out, it is worth mentioning that for $\mathrm{R}$ equal to zero, the output exhibits a singularity, which is geometrically pretty obvious (bonded surface with infinite curvature) and in mathematics translates into a vertical asymptote. Finally, the beneficial effect of the concave surface is worth noting (load carrying capacity strongly increases due to appearance of compression normal stresses on the bonded surface of the pillar). 

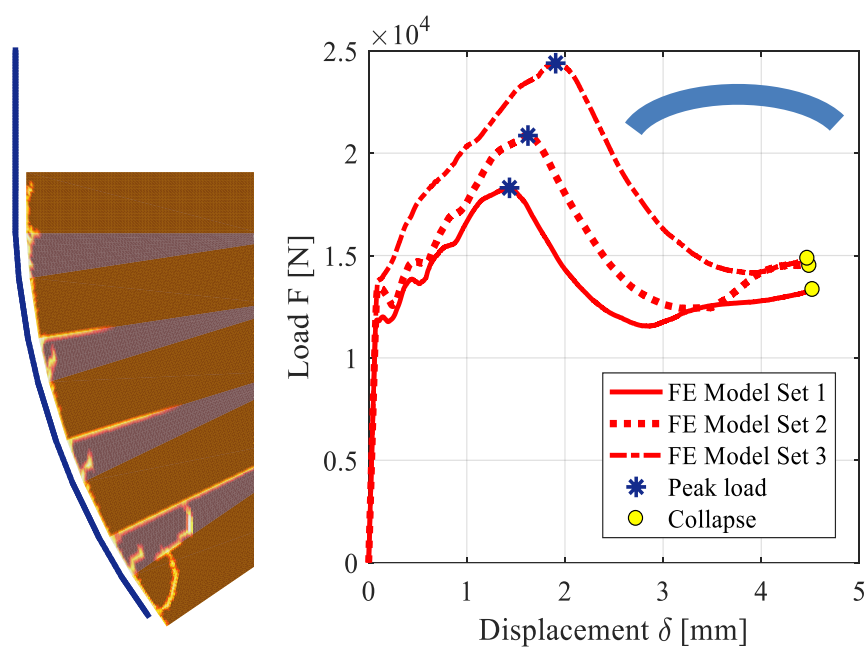

\section{$\mathrm{R}=500 \mathrm{~mm}$}
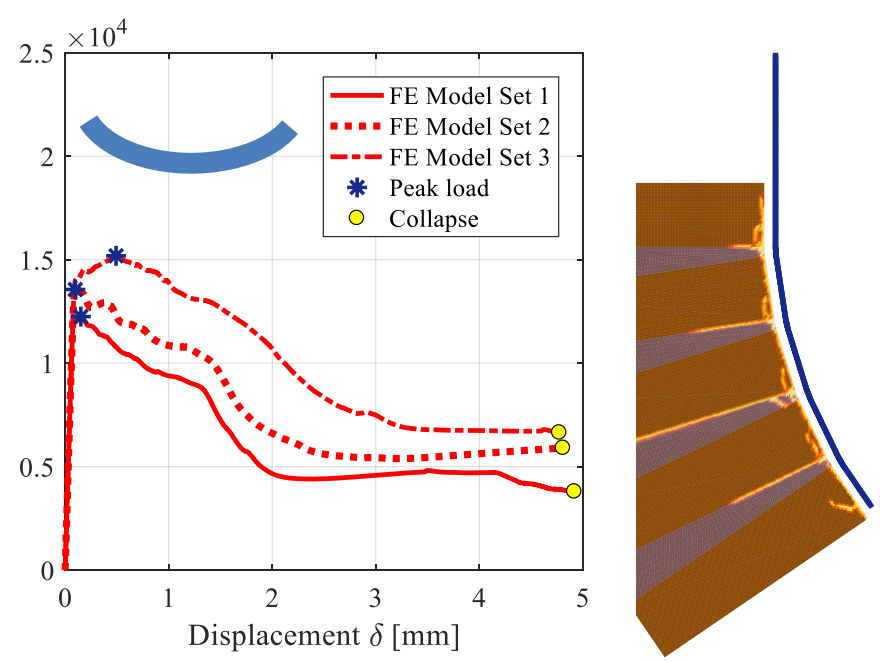

\section{$\mathrm{R}=750 \mathrm{~mm}$}
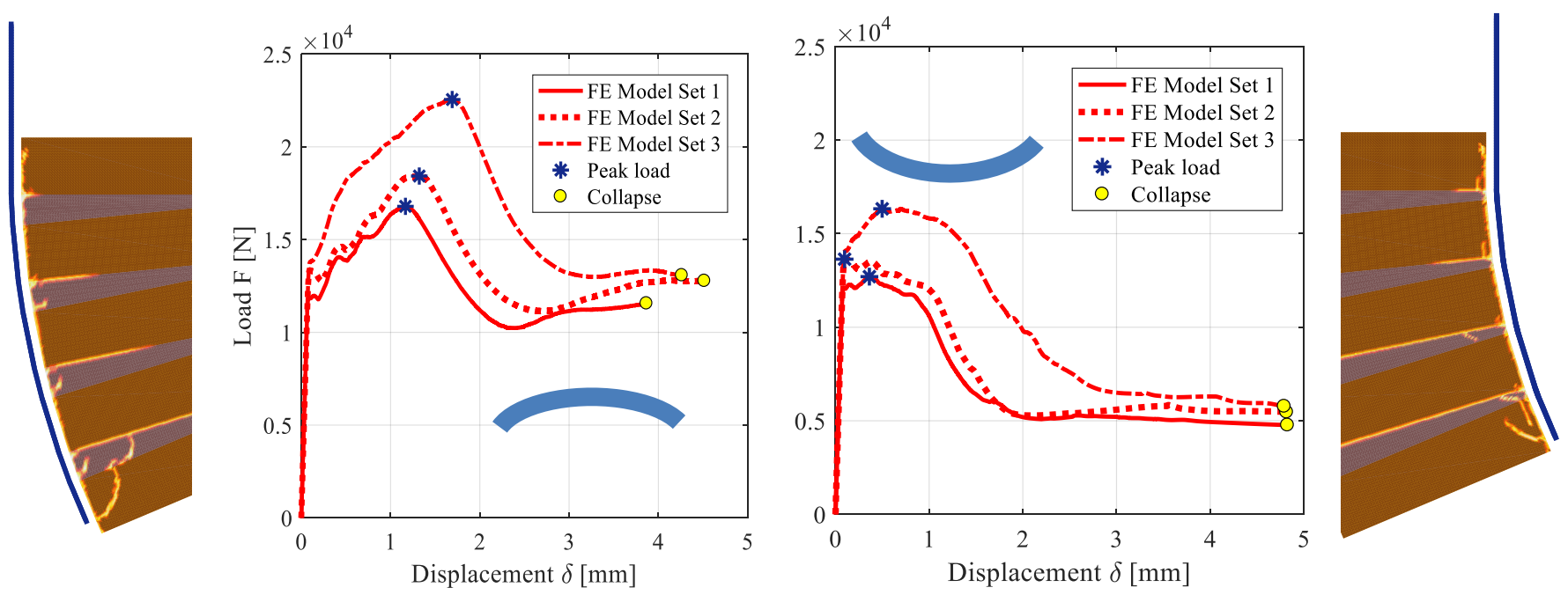

$\mathrm{R}=6000$ (quasi flat case)
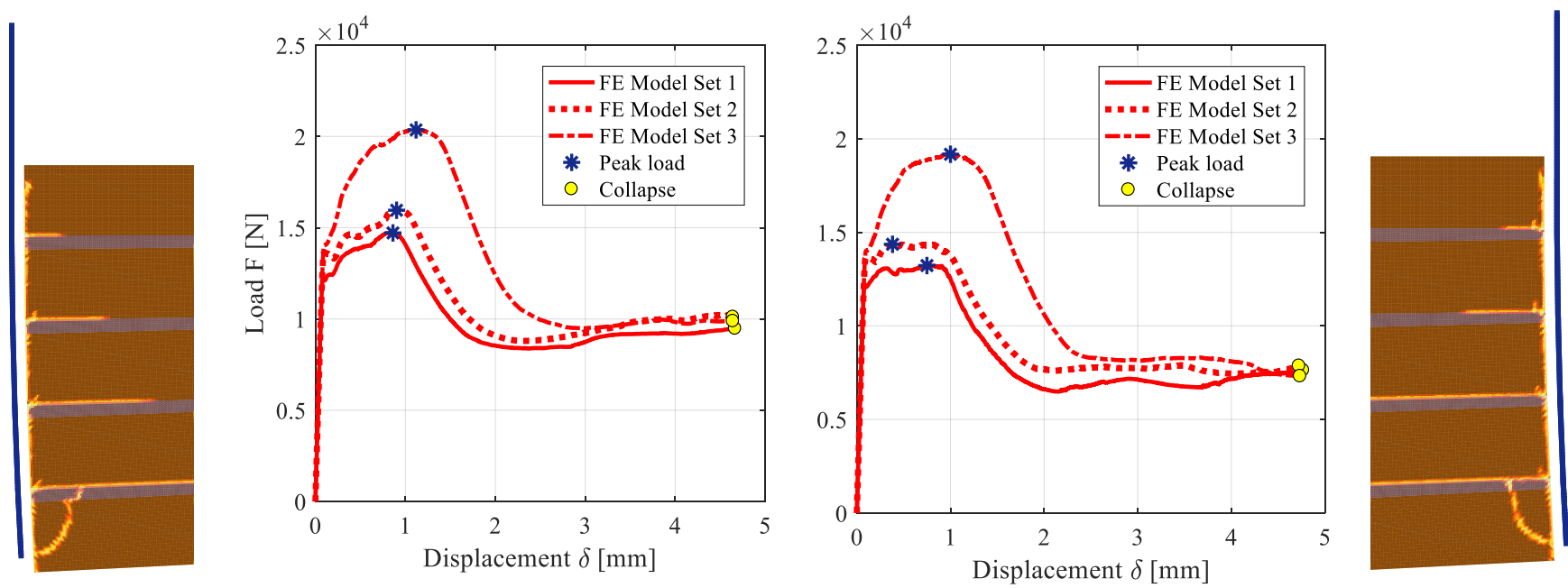

Figure 16: Global load displacement curves for curvature radii equal to 500 (top), 750 (middle) and 6000 (bottom), with the corresponding fully developed crack patters. 


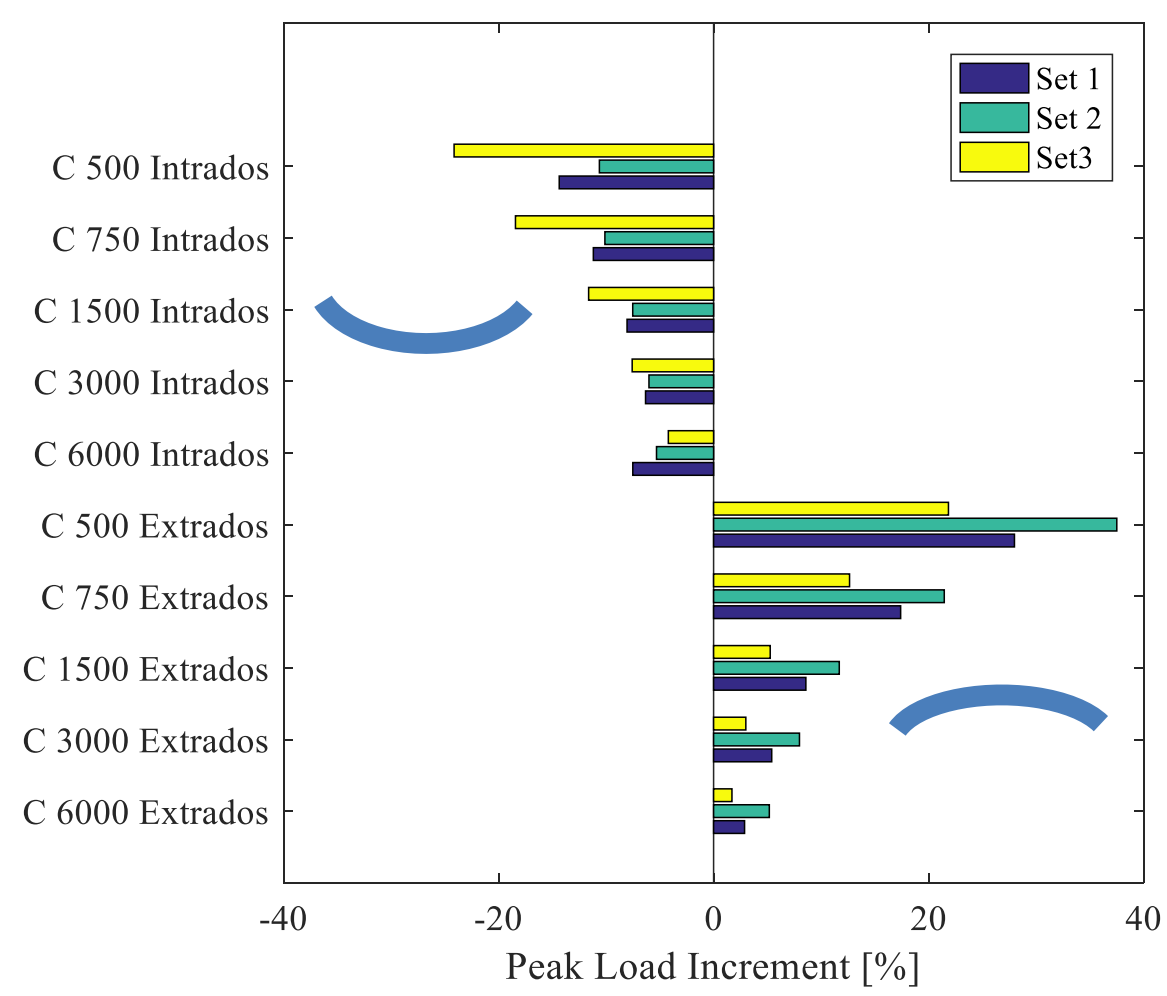

Figure 17: Peak loads increases/decreases calculated with respect to the flat configuration.

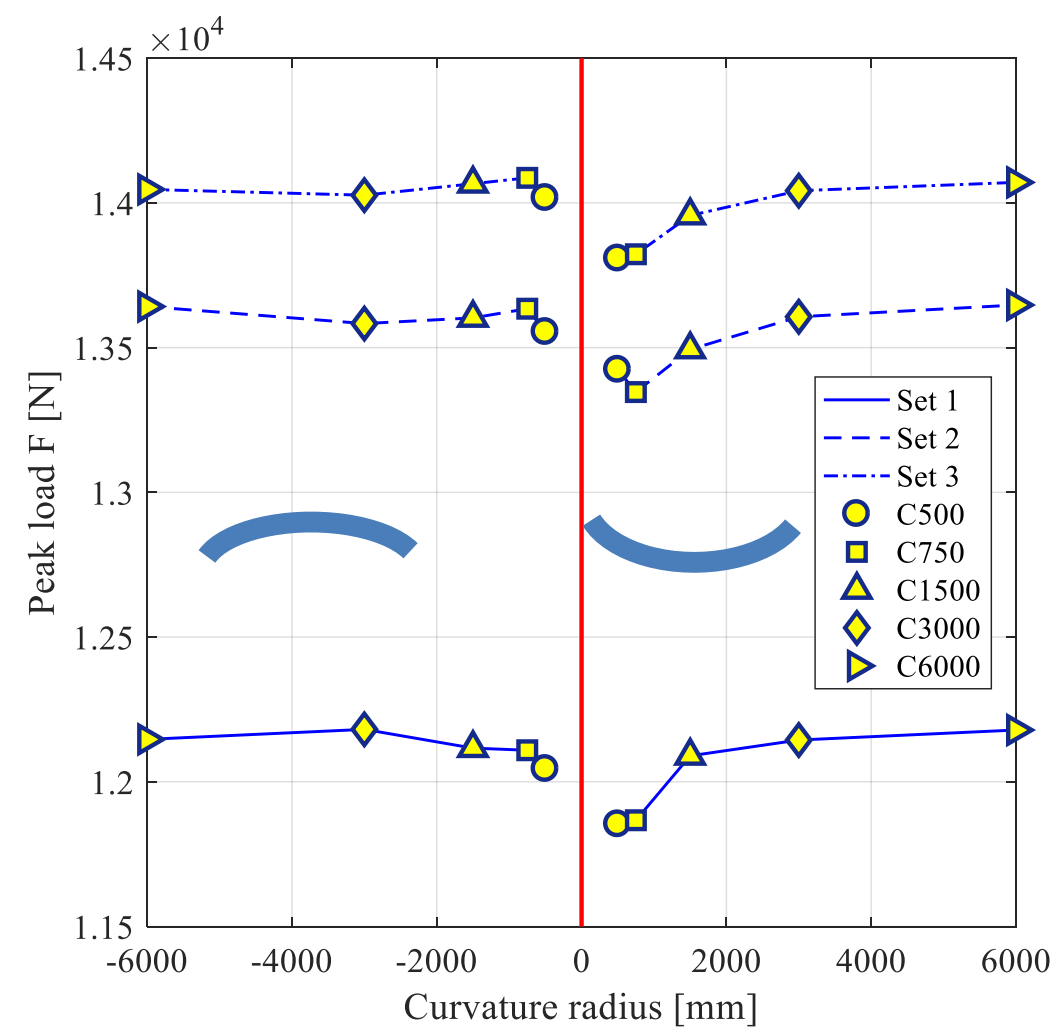

Figure 18: Force at the elastic limit for intrados and extrados strengthened pillars considering all the curvatures analyzed and the three sets of mechanical properties. 
Revised version, modifications highlighted in color YELLOW

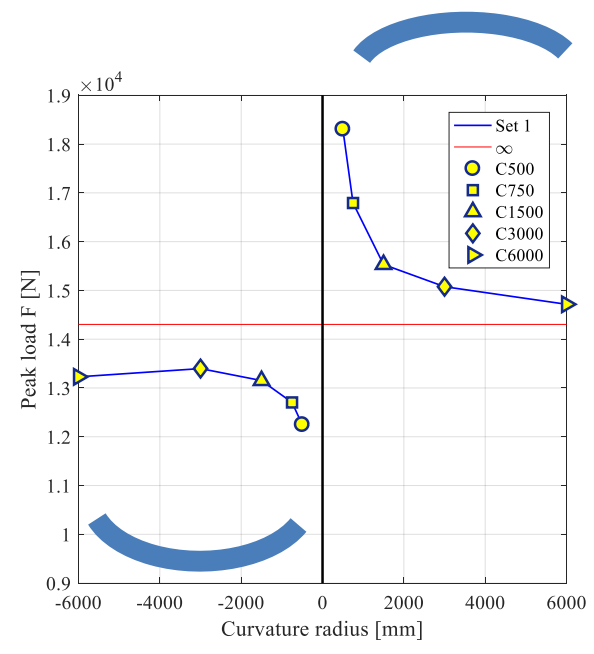

$-\mathrm{a}$

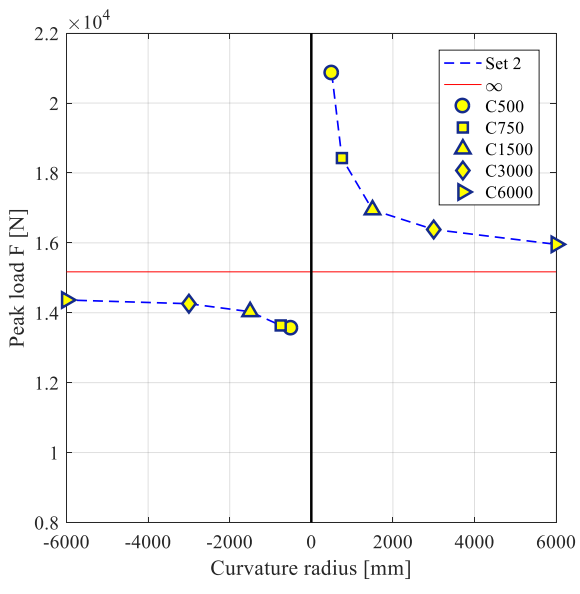

$-b$

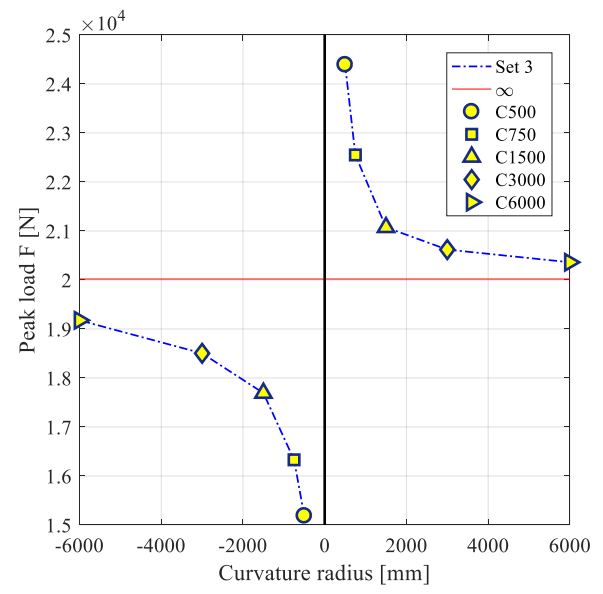

$-\mathrm{c}$

Figure 19 Peak load for intrados and extrados strengthened specimens considering all the curvatures numerically tested. -a: Set 1; -b: Set 2; -c: Set 3.

\section{Conclusions}

The paper discussed in detail a number of numerical results obtained analyzing four FRP-reinforced concave and convex masonry prisms by means of a sophisticated 2D plane-strain heterogeneous micro-modelling approach. The models were implemented into the FE commercial software Abaqus. In detail, all the constituent materials involved into the analyses were modelled separately using both elasto-plastic with damage (CDP model) four-noded (bricks and mortar) and elastic (FRP) shell elements. In addition, an elastic traction-separation cohesive interface was interposed between the FRP and the masonry support. Globally, authors observed an excellent description of the behaviors of the tested specimens. In detail, global forcedisplacement curves and damage patterns obtained fitted well with experimental observations, confirming the soundness of the numerical procedure adopted.

From the analyses carried out, the following remarks should be done:

- The numerical models require only the knowledge of the mechanical properties of the constituent materials to be predictive of the actual behavior, an information which can be obtained from standard laboratory tests.

- The 2D approach proposed is computationally relatively inexpensive, allowing an almost unconstrained refinement of the mesh at the FRP-to-masonry interface. According to the experimental evidences, such processing zone of few $\mathrm{mm}$ is crucial for the development of the failure mechanism and the stress-transfer between reinforcement and pillar.

- One of the main findings was that the compression fracture energy of the bricks is important for a correct determination of the peak delamination strength. Conversely, the elastic limit strength is independent by the curvature of the bonded surface.

- Finally, the residual strength is independent from the fracture energy chosen for the constituent materials. 
The beneficial or detrimental effect produced by the curved geometry of the bonded surface was captured properly. The computational effort needed by the FE model proposed is relatively limited; as a consequence, full sensitivity analyses are possible without difficulties. This allows predicting the debonding behavior in different conditions, for instance for different curvatures of the bonded surface, geometries and mechanical properties of the constituent materials. This latter potential generalization is intriguing, because it allows to be predictive without any need to perform expensive experimentation, offering food for thought on the possibility to propose simplified formulas to determine the delamination strength in presence of curved surfaces.

\section{References}

[1] Triantafillou TC. Strengthening of masonry structures using epoxy-bonded FRP laminates. Journal of Composites for Constructions 1998; 2(2): 96-104.

[2] Capozzucca R. Experimental FRP/SRP-historic masonry delamination. Composite Structures 2010; 92: 891-903.

[3] Aiello MA, Sciolti SM. Bond analysis of masonry structures strengthened with CFRP sheets. Construction and Building Materials 2006; 20: 90-100.

[4] Rotunno T, Rovero L, Tonietti U, Briccoli Bati S. Experimental Study of Bond Behavior of CFRPto-Brick Joints. J Compos Constr 2015;19:4014063. doi:10.1061/(asce)cc.1943-5614.0000528.

[5] Caggegi C, Pensee V, Fagone M, Cuomo M, Chevalier L. Experimental global analysis of the efficiency of carbon fiber anchors applied over CFRP strengthened bricks. Constr Build Mater 2014;53:203-12. doi:10.1016/j.conbuildmat.2013.11.086.

[6] Grande E, Imbimbo M, Sacco E. Bond behaviour of CFRP laminates glued on clay bricks: experimental and numerical study. J Compos Constr 2011; 42(2): 330-340.

[7] Zhang S, Yang D, Sheng Y, Garrity SW, Xu L. Numerical modelling of FRP-reinforced masonry walls under in-plane seismic loading. Construction and Building Materials 2017; 134: 649-663.

[8] Batikha M, Alkam F. The effect of mechanical properties of masonry on the behavior of FRPstrengthened masonry-infilled RC frame under cyclic load. Composites Structures 2015; 134: 513522.

[9] Gattulli V, Lampis G, Marcari G, Paolone A. Simulations of FRP reinforcement in masonry panels and application to a historic façade. Engineering Structures 2014; 75: 604-618.

[10] Fagone M, Rotunno T, Briccoli Bati S. The Groin Vaults of St. John Hospital in Jerusalem: An Experimental Analysis on a Scale Model. Int J Archit Herit 2016;10:903-918. doi:10.1080/15583058.2016.1158331.

[11] Briccoli Bati S, Fagone M, Rotunno T. Lower Bound Limit Analysis of Masonry Arches with CFRP Reinforcements: A Numerical Method. J Compos Constr 2013;17:366. doi:10.1061/(asce)cc.19435614.0000350 .

[12] Oliveira DV, Basilio I, Lourenco PB. Experimental behavior of FRP strengthened masonry arches. Journal of Composites for Construction 2010; 14(3): 312-322.

[13] Borri A, Castori G, Corradi M. Intrados strengthening of brick masonry arches with composite materials. Composites: Part B 2011; 42: 1164-1172.

[14] Corradi M, Borri A, Castori G, Coventry K. Experimental analysis of dynamic effects of FRP reinforced masonry vaults. Materials 2105; 8: 8059-8071.

[15] Valluzzi MR., Valdemarca M, Modena C. Behavior of brick masonry vaults strengthened by FRP laminates. Journal of Composites for Construction 2001; 5(3): 65-71. 
[16] Foraboschi P. Strengthening of masonry arches with fiber-reinforced polymer strips. Journal of Composites for Construction 2004; 8(3): 191-202.

[17] CNR DT 200/R1. Guide for the design and construction of externally bonded FRP systems for strengthening existing structures. C.N.R. National Research Council, Italy; 2013.

[18] Yang QS, Qin HQ, Zheng DH. Analytical and numerical investigation of interfacial stresses of FRPconcrete hybrid structure. Composite Structures 2002; 57: 221-226.

[19] Jiang WG, Zhong RZ, Qin QH, Tong YG. Homogenized finite element analysis on effective elastoplastic mechanical behaviors of composite with imperfect interfaces. International Journal of Molecular Sciences 2014; 15: 23389-23407.

[20] Luccioni B, Rougier VC. Shear behaviour of brick-mortar interface in CFRP retrofitted or repaired masonry. International Journal of Mechanical Sciences 2010; 52: 602-611.

[21] Ghiassi B, Marcari G, Oliveira DV, Lourenço PB. Numerical analysis of bond behavior between masonry bricks and composite materials. Engineering Structures 2012; 43: 2010-2020.

[22] Rabinovitch O. An extended high order cohesive interface approach to the debonding analysis of FRP strengthened beams. International Journal of Mechanical Sciences 2014; 81: 1-16.

[23] Teng JG, Yuan H, Chen JF. FRP-to-concrete interfaces between two adjacent cracks: theoretical model for debonding failure. Int J Solids Struct 2006; 43 (18-19): 5750-5778.

[24] Grande E, Milani G. Modeling of FRP-strengthened curved masonry specimens and proposal of a simple design formula. Compos Struct 2016;158:281-90.

[25] Wang J. Cohesive zone model of intermediate crack-induced debonding of FRP-plated concrete beam. International Journal of Solids and Structures 2006; 43 (21): 6630-6648.

[26] Fedele R, Milani G. A numerical insight into the response of masonry reinforced by FRP strips. The case of perfect adhesion. Composite Structures 2010; 92: 2345-2357.

[27] Fedele R, Milani G. Three-dimensional effects induced by FRP-from-masonry delamination. Composite Structures 2011; 93(7): 1819-1831.

[28] Fedele R, Milani G. Assesment of bonding stresses between FRP sheets and masonry pillars during delamination tests. Composites Part B: Engineering 2012; 43(4): 1999-2011.

[29] Rotunno T, Fagone M, Bertolesi E, Grande E, Milani G. Single lap shear tests of masonry curved pillars externally strengthened by CFRP strips. Under review 2018

[30] Grande E, Imbimbo M, Sacco E. Simple model for the bond behavior of masonry elements strengthened with FRP. J Compos Constr 2011;15 (3):354-63.

[31] Grande E, Milani G. Modeling of FRP-strengthened curved masonry specimens and proposal of a simple design formula. Composite Structures 2016; 158:281-290.

[32] Valluzzi MR, Oliveira DV, Caratelli A, Castori G et al. Round robin test for composite-to-brick shear bond characterization. Materials and Structures 2012; 45(12):1761-1791.

[33] Abaqus. Release 6.3. Theory and user's manuals. Pawtucket (RI, USA): Hibbit, Karlsson and Sorensen Inc.; 2003.

[34] Valente M, Milani G. Non-linear dynamic and static analyses on eight historical masonry towers in the North-East of Italy. Engineering Structures 2016; 114: 241-270.

[35] Matlab User's Guide. <http://www.mathworks.com/products/matlab/>; 2007. 